University of California, Hastings College of the Law UC Hastings Scholarship Repository

Faculty Scholarship

2017

\title{
Design Thinking: The Answer to the Impasse Between Innovation and Regulation
}

Alice Armitage

UC Hastings College of the Law, armitagea@uchastings.edu

Andrew K. Cordova

Rebecca Siegel

Follow this and additional works at: https://repository.uchastings.edu/faculty_scholarship

\section{Recommended Citation}

Alice Armitage, Andrew K. Cordova, and Rebecca Siegel, Design Thinking: The Answer to the Impasse Between Innovation and Regulation, 2 Geo. L. Tech. Rev. 3 (2017).

Available at: https://repository.uchastings.edu/faculty_scholarship/1569

This Article is brought to you for free and open access by UC Hastings Scholarship Repository. It has been accepted for inclusion in Faculty Scholarship by an authorized administrator of UC Hastings Scholarship Repository. 


\title{
DESIGN THINKING: THE ANSWER TO THE IMPASSE BETWEEN INNOVATION AND REGULATION
}

\author{
Alice Armitage, Andrew K. Cordova, and Rebecca Siegel* \\ Cite As: 2 Geo. L. TeCH. ReV. 3 (2017) \\ https://perma.cc/FWT8-66NS
}

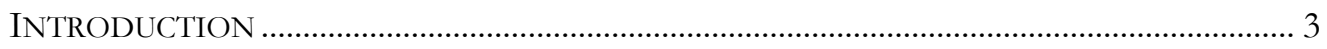

I. HOW THE BATTLE LINES WERE DRAWN ….............................................................. 9

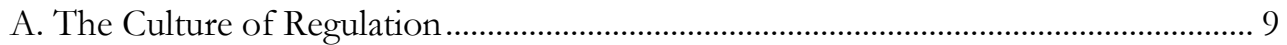

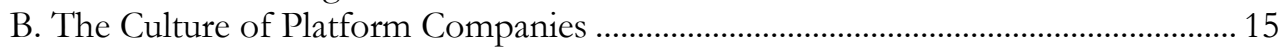

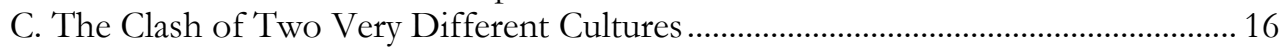

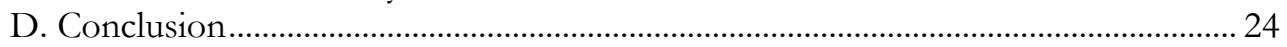

II. REACTIVE REGULATORS AND UNCOOPERATIVE COMPANIES .................................. 24

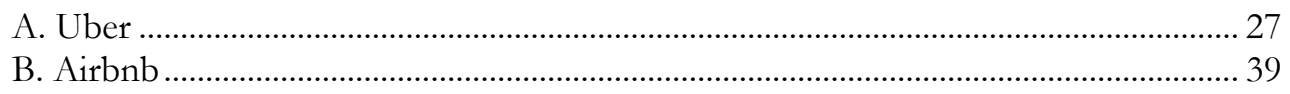

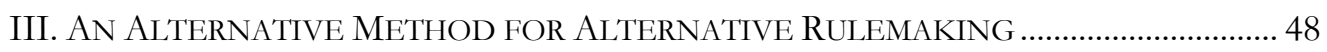

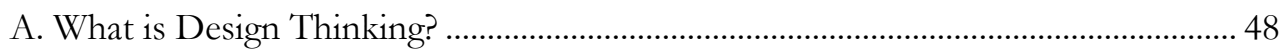

B. Design Thinking in the Private Sector..................................................................... 50

C. Applying Design Thinking to the Regulatory Process ................................................ 52

D. How Implementation of Design Thinking Could Address Harms Caused by

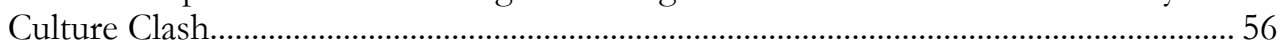

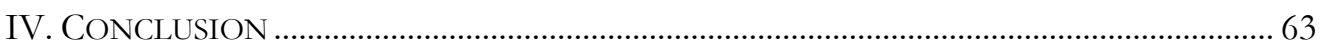

The Benefits of a Design-Thinking-Based Regulatory Process....................................... 63

\section{INTRODUCTION}

San Francisco is the home of the platform economy. ${ }^{1}$ Uber and Airbnb - the poster children of that economy-launched their initial products

\footnotetext{
* Alice Armitage is Associate Professor \& Director, Startup Legal Garage, Institute for Innovation Law, University of California Hastings College of the Law. At the time of the writing of this article, Andrew K. Cordova was Executive Director of the Institute for Innovation Law. He is now an employee of Stripe in San Francisco. Rebecca Siegel is Program Associate at the Institute of Innovation Law of the University of California Hastings. (C) 2017, Alice Armitage, Andrew K. Cordova, and Rebecca Siegel.

${ }^{1}$ See Peter C. Evans \& Annabelle Gawer, Ctr. for Glob. Enter., The Rise of the PLATFORM ENTERPRISE: A GLOBAL SURVEY 11 (2016), https://thecge.net/wp-
} 
in the city and used the feedback garnered from Bay Area users to perfect their business models. ${ }^{2}$ These and other platform companies also started to build their loyal user bases with Bay Area consumers. ${ }^{3}$ But, if San Francisco nurtured Uber and Airbnb, ${ }^{4}$ New York helped them grow. ${ }^{5}$ Based on news stories of what was happening in San Francisco and New York, the tech

content/uploads/2016/01/PDF-WEB-Platform-Survey_01_12.pdf [https://perma.cc/4HACJ2Z8] ("The highest concentration of platform headquarters is found in the San Francisco Bay Area."); see also The Online Platform Economy: Who Earns the Most?, JP MORGAN CHASE INST. (May 5, 2016) https://www.jpmorganchase.com/corporate/institute/insight-onlineplatform-econ-earnings.htm [https://perma.cc/MC6A-EFT2] ("West Coast cities are the epicenter of the Online Platform Economy, with San Francisco topping the charts.").

${ }^{2}$ See There's an App for That, ECONOMIST (Dec. 30, 2014), https://www.economist.com/news /briefing/21637355-freelance-workers-available-moments-notice-will-reshape-nature-compan ies-and [https://perma.cc/7JHY-JHR3]; Biz Carson, How Three Guys Turned Renting an Air Mattress in Their Apartment into a \$25 Billion Company, BUS. INSIDER (Feb. 23, 2016, 11:22 AM), http://www.businessinsider.com/how-airbnb-was-founded-a-visual-history-2016-2 [https://perma.cc/9BWS-J3MN] (describing Airbnb's initial launch as airbedandbreakfast.com in San Francisco).

${ }^{3}$ Brad Stone, The Upstarts: How Uber, Airbnb, AND the Killer COMPANIES OF THE NeW Silicon Valley ARE Changing THE World 107-24 (2017) (describing Uber's growth in San Francisco); LeIgh Gallagher, The Airbnb StORY: How Three ORdinary GuYs DisRUPTED AN INDUSTRY, MAdE BILliONS ... AND CREATED PleNTY OF CONTROVERSY 8-23 (2017); cf. Ryan Lawler, On-Demand Delivery Startup Postmates Raises \$16 Million from Spark Capital, TECHCRUNCH (Feb. 18, 2014), https://techcrunch.com/2014/02/18/postmates16m-spark-capital/ [https://perma.cc/PW3P-VY8Z] (noting that Postmates launched in San Francisco and has grown in subsequent markets).

${ }^{4}$ The availability and value of the tech community in San Francisco as a source of early adopters to give feedback on a new product or service is recognized by many entrepreneurs. See, e.g., Morgan Brown, Uber-What's Fueling Uber's Growth Engine?, GROWTHHACKERS (2013), https://growthhackers.com/growth-studies/uber [https://perma.cc/E3EN-6BJF] ("Uber knew that launching in San Francisco meant that they would be interacting regularly with the tech community who are continually looking for new tools and services that improve their quality of life.").

${ }^{5}$ Airbnb found users for its services in New York in 2008, and quickly realized better photographs of listed properties were essential to attract bookings. See GALLAGHER, supra note 3, at 27; see also Jenna Wortham, With a Startup Company, a Ride Is Just a Tap of an App Away, N.Y. TIMES (May 3, 2011), http://www.nytimes.com/2011/05/04/technology/04rid e.html [https://nyti.ms/2qjdWaI] ("New York is a different beast than San Francisco when it comes to public transportation, and in much of the city there is often no shortage of ways to get around."). 
community and others nationwide began to catch wind of the disruption that was heading their way. ${ }^{6}$

This disruption would not just involve new products and services affecting existing businesses. It would also serve as notice of the regulatory challenges that followed the entry of Uber and Airbnb into each new market. Government officials in California and the state of New York made national headlines as they struggled to apply existing consumer protections and licensing fees to these innovative services. ${ }^{7}$ In many ways, the states of California and New York and the cities of San Francisco and New York became crucibles for the development of regulatory policies to govern companies such as Uber and Airbnb. These solutions were often used as templates in other jurisdictions. ${ }^{8}$ Nevertheless, it has been anything but a smooth process for government officials, entrepreneurs, or consumers.

${ }^{6}$ See, e.g., Michael Arrington, Huge Vote of Confidence: Uber Raises $\$ 11$ Million from Benchmark Capital, TECHCRUNCH (Feb. 14, 2011), https://techcrunch.com/2011/02/14/hugevote-of-confidence-uber-raises-11-million-from-benchmark-capital/ [https://perma.cc/53MLJ5AE] (describing Uber's innovation and post-money valuation of $\$ 60$ million within eight months of initial launch in San Francisco); Scott Austin, Airbnb: From Y Combinator to $\$ 112 M$ Funding in Three Years, WALL ST. J. (July 25, 2011), https://blogs.wsj.com/ventureca pital/2011/07/25/airbnb-from-y-combinator-to-112m-funding-in-three-years/

[https://perma.cc/V2JL-FMQF] (describing the growth of Airbnb after being accepted into Y Combinator).

${ }^{7}$ See Anthony Ha, California Regulator Passes First Ridesharing Rules, a Big Win for Lyft, Sidecar, and Uber, TECHCRUNCH (Sept. 19, 2013), https://techcrunch.com/2013/09/19/cpucridesharing-regulations/ [https://perma.cc/JCN8-VHT5]; see also Vauhini Vara, Uber, Lyft, and Liability, NEW YORKER (Nov. 4, 2014), https://www.newyorker.com/business/currency/u ber-lyft-liability [https://perma.cc/S54Q-A8DC] (noting liability concerns for both Uber and Airbnb); cf. Ryan Lawler, Airbnb Will Begin Collecting Transient Occupancy Taxes for San Francisco Bookings Next Month, TECHCRUNCH, (Sept. 17, 2014), https://techcrunch.com/201 4/09/17/airbnb-sf-occupancy-taxes/ [https://perma.cc/KWF7-NXVE].

${ }^{8}$ See Emma Hinchliffe, No Vacancy: How Airbnb's New York City Problem Is Just Getting Worse, MASHABLE, http://mashable.com/2017/04/03/airbnb-nyc-no-vacancy/\#Zbv5o8QcFPq $\mathrm{h}$ [https://perma.cc/T7EH-VW4J] ("[O]ther cities that are growing in dissatisfaction with the company's rapid takeover are watching for tips on how to fight their own battles."); see also Tomio Geron, California Becomes First State to Regulate Ridesharing Services Lyft, Sidecar, UberX, FORBES (Sept. 19, 2013), https://www.forbes.com/ sites/tomiogeron/2013/09/19/california-becomes-first-state-to-regulate-ridesharing-serviceslyft-sidecar-uberx/\#75f3f51b1804 [https://perma.cc/F2LN-YEMW] (discussing California's rules and their potential as a model for other states). 
Headlines about the ongoing battles fill news feeds even now, almost 10 years after Uber and Airbnb were founded. ${ }^{9}$

This article begins by examining how the different characteristics and cultures of Silicon Valley and City Hall set the scene for the confrontations to come. With that context in mind, we dive into the specifics of the battles between Uber and Airbnb on one side and California and New York regulators on the other. Those specifics help to illuminate why and how the current regulatory system is ill equipped to achieve its goals-consumer safety, competitive fairness, and nondiscrimination, among others ${ }^{10}$ - while also supporting innovation and technological change.

These regulatory struggles have harmed everyone involved. Consumers have not been fully protected as they try out platform company services; regulators and policymakers have spent untold hours and government funds attempting to enforce existing regulations; and Uber and Airbnb have paid huge fees, penalties, and litigation costs as their battles have moved to the courts. ${ }^{11}$ Moreover, society in general is harmed as important policy and economic goals are often lost on the battleground of innovation versus regulation. ${ }^{12}$

\footnotetext{
${ }^{9}$ Winnie Hu, As Uber Woos More Drivers, Taxis Hit Back, N.Y. TIMES, (Mar. 18, 2017) https://www.nytimes.com/2017/03/18/nyregion/nyc-taxi-center-uber.html [https://nyti.ms/2nDhhQD]; Megan Rose Dickey, Airbnb Settles Lawsuit with San Francisco, TECHCRUNCH, (May 1, 2017) https://techcrunch.com/2017/05/01/airbnb-settles-lawsuit-withsan-francisco/_[https://perma.cc/LJ4V-NPSV].

${ }^{10}$ See, About the California Public Utilities Commission (CPUC), CAL. Pub. UTILs. Comm'N, http://cpuc.ca.gov/aboutus/ [https://perma.cc/C7ZS-7QBX]; see also N.Y.C. Taxi and Limo Comm'n, About TLC, NYC.GOV, http://www.nyc.gov/html/tlc/html/about/about.shtml [https://perma.cc/SQ82-2X67]; S.F. ADMIN. CODE § 41A.2. (2017).

11 Heather Kelly, Uber's Never-ending Stream of Lawsuits, CNN (Aug. 11, 2016), http://money.cnn.com/2016/08/11/technology/uber-lawsuits/index.html

[https://perma.cc/A2ZW-3MM3]. In 2016, Airbnb filed a number of lawsuits in federal court to head off restrictive rules issued by local regulators after the company refused to cooperate with prior laws. See text, infra at Part II, Section A(2). In San Francisco, Airbnb has had to accept criminal liability if it fails to comply with city short-term rental laws. S.F. ADMIN. CODE $§$ 41A.5.e (2017).

${ }^{12}$ In 2014, the Supreme Court ruled against television show streaming company Aereo in a decision that ultimately led to its bankruptcy. Emily Steel, Aereo Concedes Defeat and Files for Bankruptcy, N.Y. TIMES (Nov. 21, 2014), https://www.nytimes.com/2014/11/22/busin ess/aereo-files-for-bankruptcy.html [https://nyti.ms/2my0gGZ]. Digital health companies with mobile native apps that track user consumption and activity face a number of regulatory hurdles. See Samuel Waxman et al., Legal Health Isn't Easy for Digital Health Companies, TECHCRUNCH (Apr. 13, 2016), https://techcrunch.com/2016/04/13/legal-good-
} 
These issues are not new. Regulatory history is replete with examples of innovative businesses in high demand by consumers-think railroads, telephone, and airlines ${ }^{13}$ - that regulators took "command" of to ensure consumer safety and prevent price gouging and other unfair business practices. After decades of use, many of these regulations failed to function effectively as business and society changed. In response, all these industries were ultimately deregulated, creating another set of problems. Is there no other path for innovative, high-growth businesses other than strictly regulated or unregulated? In this article, we posit that there is.

In Part I, we discuss how regulators and platform companies arrived at this point of tension. In Part II, we detail how regulators' attempts to control Uber and Airbnb resulted in harm to both sides. In Part III, we suggest a better way to regulate innovative companies.

We know that new disruptive technologies are just around the corner whether they are autonomous vehicles, smart contracts on blockchain platforms, ambient artificial intelligence systems in our homes and cars, or something yet to be envisioned. How do we prepare to regulate technology we do not really understand yet? We argue that this can be achieved by creating a collaborative, flexible, nimble process of regulation that involves all industry and regulatory stakeholders. In current models of regulation, this is not

health-isnt-easy-for-digital-health-companies/ [https://perma.cc/JBG3-TAVZ]. The SEC has made a number of fintech founders nervous by opening up new conversations on regulation. See Nik Milanovic, An Obscure Regulatory Debate Has Put the Entire U.S. Fintech Community on Edge, TECHCRUNCH (Apr. 24, 2017), https://techcrunch.com/2017/04/24/anobscure-regulatory-debate-has-put-the-entire-u-s-fintech-community-on-edge/

[https://perma.cc/U9U7-K9C7].

${ }^{13}$ Although not widely known to be the beginning of the American administrative state, the steamboat industry was the first large-scale American industry to be regulated at the local, then state, and then national level. Intense competition along the Mississippi River led to reckless steamboat driving and fatal steam engine explosions along the busy trade route. As a result, The Steamboat Act of 1837 was written to protect consumers and consumer goods. The 1837 Act relied on private enforcement mechanisms. It was followed up by the Steamboat Act of 1853, which removed the private enforcement mechanisms and applied administrative adjudications such as fines or the revocation of a license. Railroads went through a similar regulatory path. Economic downturns, safety concerns, and a need for regulatory continuity between states led Congress to enact the Interstate Commerce Act, which gave Congress the right to regulate interstate railroads to protect consumers and facilitate healthy competition. See Reuel Schiller, The Historical Origins of American Regulatory Exceptionalism, in Comparative LAW AND Regulation: Understanding the Global Regulatory PROCESS 55-70 (Francesca Bignami \& David Zaring eds., 2016). 
possible, ${ }^{14}$ but in Part III, we explore whether there is a way to create a different regulatory process by utilizing principles of design thinking, a method that has proven its worth in product design, system design, and infrastructure design, and is now making its way into the processes of government. ${ }^{15}$ We provide an understanding of design thinking in general and then detail the steps involved to create a new regulatory process using design thinking. ${ }^{16}$ By putting such a regulatory process in place, consumers and innovative businesses will know that both society's best interests and innovation will be supported regardless of when the next disruption appears.

\footnotetext{
${ }^{14}$ Many regulatory processes include a notice and comment period during which businesses and members of the public can suggest changes to proposed rules. See OFFICE OF THE FED. REGISTER, GUIDE TO THE RULEMAKING PROCESS, https://www.federalregister.gov/uploa ds/2011/01/the_rulemaking_process.pdf [https://perma.cc/YSR9-CMJ3] (describing how comments are solicited from the public and how those comments are used by agencies to issue final rules); CAL OfFice of AdMIN. LAW, Guide to Public PARTICIPATION IN THE REGULATORY PROCESS, https://www.oal.ca.gov/wp-content/uploads/sites/28/2017/05/How-2Participate-102016.pdf [https://perma.cc/8UWS-8XPZ] (describing the notice and comment process in California).

${ }_{15}$ See generally Christian Bason, Design-Led Innovation in Government, STAN. SoC. INNOVATION REV. 16 (Spring 2013), https://ssir.org/articles/entry/design_led_innovation_in_ government [https://perma.cc/67RN-CVHM] (discussing both private industry and public agencies adopting design thinking for public purposes); GLOB. CTR. FOR PUB. SERV. EXCEllence, Design ThINkING FOR Public SERvice EXCEllence (2014), http://www.undp.org/content/undp/en/home/librarypage/capacity-building/global-centre-forpublic-service-excellence/DesignThinking.html [https://perma.cc/M8D8-9BYA].

${ }^{16}$ Design thinking has already been utilized to recommend changes to governmental systems in Canada, Denmark, and other countries around the world. See JOERI VAN DEN STEENHOVEN ET AL., Shifting Perspectives: Redesigning Regulation for the SHARING ECONOMY (2016), https://www.marsdd.com/wp-content/uploads/2016/04/MSL-Sharing-EconomyPublic-Design-Report.pdf [https://perma.cc/62B9-9D35] (using design thinking principles to rethink regulation for the City of Toronto); Bason, supra note 15, at 16 ("In Denmark, design has already been applied in a wide range of public sector settings"); June Gwee, Redesigning Employment Pass Application in Singapore, ThIS Is Design THINKING (June 15, 2015), http://thisisdesignthinking.net/tag/government [https://perma.cc/G398-P3N3] ("Design thinking can potentially transform the perception and meaning of public service.").
} 


\section{HOW THE BATTLE LINES WERE DRAWN ${ }^{17}$}

The rulemaking procedures for the federal government and the state of California have been in place since the mid-1940s. ${ }^{18}$ They were designed to work well with a business models that are different from those used by many platform companies today. For that reason, there is inherent tension between existing rules and the models used by platform companies to offer services in new ways.

\section{A. The Culture of Regulation}

Regulations have not always kept up in times of rapid change. ${ }^{19}$ This inability to adapt quickly can be traced to the increasing complexity of regulation and the changing perspectives and theories concerning the goals of regulation that drove that complexity throughout its history. ${ }^{20}$

The history of regulation in the United States is most often traced back to the rules promulgated in the second half of the nineteenth century by the

\footnotetext{
${ }^{17}$ We would like to thank all the participants in the ReWIRE Events hosted by UC Hastings and the Office of Kamala Harris, California Attorney General in 2016. ReWIRE was attended by both former and current regulators and entrepreneurs at new and established companies in the platform economy, and was designed as a deep dive into the issues that are at the forefront of this paper. In order to allow for full and frank discussions, we promised all participants we would not quote or attribute anything directly, which we have not done. Nevertheless, many of our arguments were inspired by their terrific insights and detailed discussions of the impasse.

${ }^{18}$ Cynthia Tripi, Administrative Law, 55 GEO. WASH. L. REV. 729, 729 (1987); John G. Clarkson, The History of the California Administrative Procedure Act, 15 HASTINGS L. J. 237, 247 (1964).

${ }^{19}$ ANDREW Lo, AdAPTIVE MARKETS: FinANCIAL EVOlution AT THE SPEED OF THOUGHT 372 (2017) ("The U.S. legal system is a working example of adaptive regulation. . . . [I]t incrementally changes in response to societal needs and political pressure. However, it wasn't designed for periods of rapid change."); see also Stephen J. Groseclose, Reinventing the Regulatory Agenda: Conclusions on an Empirical Study of EPA's Clean Air Act Rulemaking Progress Projections, 53 MD. L. REV. 521, 522 (1994) ("Chronic regulatory delay and unrealistic Agenda information are symptoms of complex problems in the regulatory bureaucracy.").

${ }^{20}$ Cf. Robert Baldwin et al., Understanding Regulation: Theory, Strategy, And PRACTICE 66-67 (1999) (explaining that "[a]s the field of regulation has grown and matured, so has the discussion regarding theory" and demonstrating the varying emphases of different theories of regulation).
} 
federal government. ${ }^{21}$ At that time, public officials recognized that the government had to protect merchants and farmers from the exorbitant rates they were charged by railroad companies to ship goods across the country. ${ }^{22}$ Eventually, Congress passed the Interstate Commerce Act of $1887,{ }^{23}$ which created the first independent regulatory agency with the power to investigate corporate activities. ${ }^{24}$

More laws and regulations followed in the next several decades as the federal government exerted its power to control more industries. ${ }^{25}$ Additional agencies and regulations followed throughout the first two-thirds of the twentieth century. These included new consumer protection regulations in the $1900 \mathrm{~s}$ and 1910s, ${ }^{26}$ as well as New Deal regulations in the 1930s. ${ }^{27}$ Environmental protections, civil rights, and reduction of poverty policies all grew during the $1960 \mathrm{~s} .{ }^{28}$ At the same time, state governments were also

${ }^{21}$ See Schiller, supra note 13, at 55-70. More recently, legal scholars and historians have argued that there have been state and local rules since the United States was formed, and that those rules were the beginning of regulation in the United States. See William J. Novak, A Revisionist History of Regulatory Capture, in PREVENTING REGULATORY CAPTURE: SPECIAL INTEREST INFLUENCE AND HOW TO LIMIT IT 28-30 (including citations to works referenced) (Daniel Carpenter \& David A. Moss, eds., 2013).

${ }^{22}$ See A Brief History of Administrative Government, CTR. FOR EFFECTIVE Gov'T, http://www.foreffectivegov.org/node/3461 [https://perma.cc/A7VG-PXQ7].

${ }^{23}$ See Interstate Commerce Act (1887), OURDOCUMENTS.GOV, https://www.ourdocuments.go v/doc.php?flash=false \&doc=49 [https://perma.cc/7FRZ-NNAA].

${ }^{24}$ See Andrew Glass, Congress Approves Interstate Commerce Act, Feb. 4, 1887, POLITICO (Feb. 4, 2016 12:08 AM), https://www.politico.com/story/2016/01/congress-approvesinterstate-commerce-act-feb-4-1887-218485 [https://perma.cc/6UKG-V8VH].

25 See Jerry L. Mashaw, Creating the Administrative Constitution 13 (2012) (discussing the construction of the national administrative state in the United States).

26 See Our History, FED TRADE COMM'N, https://www.ftc.gov/about-ftc/our-history [https://perma.cc/92EL-5MZT] (noting that the FTC was created in 1914 and has the mission to protect consumers and promote competition); Part I: The 1906 Food and Drugs Act and Its Enforcement, U.S. FOOD AND DRUG ADMIN. [https://perma.cc/7UMP-7KXU], https://www.fda.gov/AboutFDA/WhatWeDo/History/Origin/ucm054819.htm.

27 Cf. Martin Kelly, Top 10 New Deal Programs of the 1930s, THOUGHTCo https://www.thoughtco.com/top-new-deal-programs-104687 [https://perma.cc/A55Q-UPPT].

28 See Mary O. Furner, From "State Interference" to the "Return of the Market": The Rhetoric of Economic Regulation from the Old Gilded Age to the New, in GOVERNMENT AND MARKETS: TOWARD A NEW THEORY OF REgulation, 131 (Edward J. Balliesen \& David A. Moss eds., 2010). 
issuing rules in areas not covered by federal regulation. ${ }^{29}$ Following these decades of rulemaking, the 1980 s and 1990s saw a wave of deregulation. ${ }^{30}$ After the financial crisis of 2008 , however, there have been calls for a return to more regulation. ${ }^{31}$

Command-and-Control regulations are mandatory rules formulated by government officials and imposed on a targeted industry. ${ }^{32}$ These sorts of rules were seen as necessary because of the impact externalities had on the efficiency of unfettered free markets. ${ }^{33}$ However, this authoritarian, top-down method came under criticism in the $1970{ }^{\prime 34}$ - a period during which the number and specificity of regulations exploded. ${ }^{35}$ Theorists began to recognize that regulations did not always accomplish their goal of controlling

${ }^{29}$ See Jonathan H. Adler, The Fable of Federal Regulation: Reconsidering the Federal Role in Environmental Protection, 55 CASE WESTERN RES. L. REV. 93, 97-98 (2004) (explaining that before the Federal Government enacted any widespread environmental regulation, states regulated businesses to protect clean air and water supplies).

${ }^{30}$ See Edward Balleisen \& David A. Moss, Introduction to GovERnMENT AND MARKETS: TOWARD A NEW THEORY OF REgulATION 1 (Edward Balleisen \& David A. Moss eds., 2009). For an analysis of the response of legal scholars to these developments, see Alice Armitage, Gauguin, Darwin \& Design Thinking: A Solution to the Impasse between Innovation and Regulation 3-4 (Dec. 16, 2016) (unpublished manuscript), https://papers.ssrn.com/sol3/papers.cfm?abstract_id=2886101 [https://perma.cc/42VVM4RD].

31 Phil Angelides, How Did Our Financial System Become So Deregulated?, PBS: FRONTLINE, http://www.pbs.org/wgbh/pages/frontline/oral-history/financialcrisis/tags/deregulation/ [https://perma.cc/7KKZ-5SJV].

${ }^{32}$ Wendell Pritchett, Types of Regulation, REG. REV. (Apr. 5, 2016), https://www.theregrevie w.org/2016/04/05/pritchett-types-of-regulation/ [https://perma.cc/HU9Y-NVJZ] ("Under [command-and-control regulation], the regulatory agency sets forth methods, materials, and the processes by which the regulated entity must operate.").

${ }^{33}$ See Balleisen \& Moss, supra note 30, at 2 (noting that in the 1950s and 1960s, regulators were understood to be on a "search and destroy mission, with market failure as the target"); cf. Joseph E. Stiglitz, Government Failure vs. Market Failure: Principles of Regulation, in GOVERNMENT AND MARKETS: TOWARD A NEW THEORY OF REGULATION 13, 15-16 (Edward Balleisen \& David A. Moss eds., 2009) (analyzing Adam Smith's theory of free markets and concluding that "the theory that markets, by themselves, lead to efficient outcomes has, in short, no theoretical justifications").

${ }^{34}$ Furner, supra note 28, at 133-34.

${ }^{35}$ Glenn Harlan Reynolds, Why We Still Don't Have Flying Cars, U.S.A. TodAY (May 12, 2016, 12:30 PM), https://www.usatoday.com/story/opinion/2016/05/12/technologicalprogress-stagnation-regulatory-explosion-1970s-column/84225066/ [https://perma.cc/HRP3JTG7] ("1970 marks what scholars of administrative law (like me) call the 'regulatory explosion."”). 
externalities ${ }^{36}$ in part because of what would come to be known as the theory of regulatory capture.

The term regulatory capture was the label given to the concepts first described by George Stigler in the early 1970s. ${ }^{37}$ Stigler posited that "every industry or occupation that has enough political power to utilize the state will seek to control entry" and that "regulatory policy will often be so fashioned as to retard the rate of growth of new firms." ${ }^{38}$ In other words, the status quo is protected by the regulations themselves, as it is difficult and often expensive for new companies to comply with complicated rules. ${ }^{39}$

These theories of "government failure" led to a call for widespread deregulation. ${ }^{40}$ These reforms, however, did not often change state and local

${ }^{36}$ Cf. Balleisen \& Moss, supra note 30, at 2-3 ("By the late 1970s, social scientists had begun ... showing increasing sensitivity to the possibility that even in the presence of market failure policymakers could potentially do more harm than good in their attempts to cure market ills."); Paul Stephen Dempsey, The Rise and Fall of the Interstate Commerce Commission: The Tortuous Path From Regulation to Deregulation of America's Infrastructure, 95 MARQ. L. REV. 1151, 1152 (2012) ("[J]ust as market failure had given rise to economic regulation, regulatory failure gave rise to deregulation.").

${ }^{37}$ Ernesto Dal Bó, Regulatory Capture: A Review, 22 OXFORD REV. ECON. POL'Y 203, 20304 (2006); see generally George Stigler, The Theory of Economic Regulation, 2 BELL J. ECON. \& MGMT. SCI. 1, 3 (1971).

${ }^{38}$ Stigler, supra note 37 , at 5. Stigler's original notion of regulatory capture has been expanded to include more nuanced analyses of how capture can occur. See generally James Kwak, Collateral Capture and the Financial Crisis, in Preventing Regulatory CAPTURE 71, 80-90 (Daniel Carpenter \& David A. Moss eds., 2014) (noting three mechanisms by which regulated industry is able to shape regulators beliefs and actions: (1) identity, (2) status, and (3) relationships).

${ }^{39}$ See David A Moss \& Daniel Carpenter, Conclusion: A Focus on Evidence and Prevention, in Preventing Regulatory Capture 451, 451-52 (Daniel Carpenter \& David A. Moss eds., 2014) (describing the original definition of regulatory capture as envisioning powerful incumbent firms paying regulators to build barriers to entry).

40 See Marc Allen Eisner, Markets in the Shadow of the State: An Reappraisal of Deregulation and Implications for Future Research, in GOVERNMENT AND MARKETS: TOWARD A New ThEORY OF REgulation 512, 512-13 (Edward Balleisen \& David A. Moss eds., 2009) (describing how theories of regulatory capture and criticism of regulation in general helped create a foundation for wide-ranging moves to deregulate markets). Deregulation, however, did not always achieve the desired results. See Dempsey, supra note 36, at 1152. The worldwide financial crisis that began in 2008 resulted in a call for the return of regulation to many industries, especially the banks. See Balleisen \& Moss, supra note 30, at 1 . 
regulation, which is still regularly criticized for being subject to regulatory capture. $^{41}$

In addition to the lack of incentives for change created by regulatory capture at the state and local level, ${ }^{42}$ other forces make new regulations difficult to implement. First, the rulemaking process is lengthy and cumbersome, and the process of revision even more so. ${ }^{43}$ Second, although an agency may begin a rulemaking process on its own initiative, in practice, the regulatory process is primarily reactive. Regulators tend to wait for a statutory mandate, a suggestion from other government official or agency, or a petition from an outside person before initiating the process to change an existing rule or write a new one. ${ }^{44}$

The result is that, even now, in the digital age, the state and local rulemaking process is slow and deliberative, waiting for changes in the marketplace to create demand for regulatory changes. ${ }^{45}$ For example, San

41 See John Cassidy, Battle of the Bike Lanes, NEW YORKER (Mar. 8, 2011), https://www.newyorker.com/news/john-cassidy/battle-of-the-bike-lanes

[https://perma.cc/Y54Y-466G]; cf. Larry Downes, Lessons from Uber: Why Innovation and Regulation Don't Mix, FORBES (Feb. 13, 2013), http://www.forbes.com/sites/larrydownes/201 3/02/06/lessons-from-uber-why-innovation-and-regulation-dont-mix/ [https://perma.cc/336TTKX9] (describing the author's bad experience using a taxi and explaining that, at the time, "Uber [could not] operate in Miami, for example, where existing laws were clearly drafted to protect taxicabs from competition even from other licensed services").

${ }^{42}$ See, e.g., Downes, supra note 41 (outlining lack of motivation for taxi drivers to adopt improvements to the service they offered).

${ }^{43}$ Lynn E. Blais \& Wendy E. Wagner, Emerging Science, Adaptive Regulation, and the Problem of Rulemaking Ruts, 86 TEX. L. REV. 1701, 1710 (2008) ("revision of existing rules may be even more likely to fall victim to the factors responsible for the ossification of initial rulemaking"); $c f$. Cal. St. Senate Republican Caucus, Briefing Report: The Riveting Regulatory Process: A Study in Bureaucracy, CSSRC.US (Mar. 13, 2013), http://cssrc.us/content/briefing-report-riveting-regulatory-process-study-bureaucracy

[https://perma.cc/F35S-HKY9] (outlining the steps necessary to propose a new rule and describing a process that will take months or years to complete).

${ }^{44}$ Richard J. Pierce, Jr., Seven Ways to Deossify Agency Rulemaking, 47 ADMIN. L. REv. 59, 61 (1995) ("[A]gencies rarely amend rules because the amendment process is as daunting as the process of promulgating a rule."); $c f$. Ronald M. Levin, A Blackletter Statement of Federal Administrative Law, 54 ADMIN. L. REV. 1, 30-36 (2002) (outlining the federal rulemaking process). The California process is similarly cumbersome and reactive. See CAL. OfFICE ADMIN. LAW, The Rulemaking Process, http://www.cfb.ca.gov/laws_regs/flowchart.pdf [https://perma.cc/RK3L-FVPL].

${ }^{45}$ For an example of one state's rulemaking process, see Flowchart of Public Rulemaking Process in California, OFFICE ADMIN. L. https://www.oal.ca.gov/wp- 
Francisco had a law on the books from the 1980s that banned all short-term rentals. ${ }^{46}$ Airbnb hosts provided short-term rentals in the city for six years before the city changed that law. One member of the Board of Supervisors said that he had been trying for two years to write new rules to govern these rentals before changes were finally made in $2014 .{ }^{47}$ Similarly, taxi companies are regulated across the country by the cities in which they operate. ${ }^{48}$ The result was an industry that had not kept up with consumer demand or technological change and thus was ripe for disruption. ${ }^{49}$ Additionally, the mechanisms available to regulators to enforce the rules were limited to punitive tools designed to control industry participants with traditional business plans. ${ }^{50}$

Consequently, the industries that the platform-economy companies set out to disrupt in the first decade of the twentieth century were subject to a regulatory process that was slow, deliberative, and reactive. While existing regulations provided a way for the public to participate, these regulations were

content/uploads/sites/28/2017/05/Regular-Rulemaking-Flowchart_FINAL_June-2014-2.pdf [https://perma.cc/E55R-CQBA] (describing at least 8 steps required to write and implement a California state regulation, including at least one and possibly two 45-day comment periods).

${ }^{46}$ Bigad Shaban, Jeremy Carroll \& Kevin Nious, Thousands Violate SF Housing Laws Using Airbnb, Few Face Penalties, NBC BAY AREA (May 19, 2016), http://www.nbcbayarea.com/in vestigations/Bay-Legal-Thousands-violate-SF-housing-laws-few-face-penalties-

380218621.html [https://perma.cc/96AG-UP4N].

${ }^{47}$ See David Chiu, San Francisco's Short-Term Rental Solution, TeCHCRUNCH (Nov. 1, 2014), https://techcrunch.com/2014/11/01/san-franciscos-short-term-rental-solution/ [https://perma.cc/XLF6-U8FP] (stating that after two-and-a-half years, the mayor of San Francisco signed a law the author wrote that will for the first time regulate short-term rentals in San Francisco).

${ }^{48}$ See Bruce Schaller, Entry Controls in Taxi Regulation: Implications of US and Canadian Experience for Taxi Regulation and Deregulation, 14 TRANSPORT POL'Y 490, 490-506 (2007) (analyzing taxi regulations in 43 North American cities, including 32 of the 50 largest taxi regulatory systems in North America as measured by the number of taxicabs). The taxi industry across the country is often cited as a prime example of regulatory capture in which the rules themselves act as a barrier to entry and so cushion incumbents from market forces. See Michael Farren, Christopher KoOpman, \& MAtThew Mitchell, Rethinking TaXi REgulations: THE CASE FOR Fundamental REFORM 7-8 (July 2016), https://www.mercatus.org/system/files/Farren_Taxi_FINAL.pdf [https://perma.cc/F8Z9FCWM].

${ }^{49}$ See Downes, supra note 41.

${ }^{50}$ Cf. Stephen R. Miller, First Principles for Regulating the Sharing Economy, 53 HARV. J. ON LEGIS. 147, 184-94 (2016) (describing the limited mechanisms, mostly in the form of punitive tools, available to regulators). 
difficult to access or understand substantively and procedurally, and were focused on past ways of doing business. ${ }^{51}$ There was no incentive for regulators to stay on top of changes in the industry they regulated, nor to make amendments to existing rules. In this way, the regulators of the hotel and taxi industries operated in a bureaucratic culture in which change was not welcomed and happened slowly, if at all.

\section{B. The Culture of Platform Companies}

Silicon Valley culture, to which entrepreneurs all over the world pay attention, is based on a few long-standing principles. One is the belief that a successful startup should be built the "lean startup" way. ${ }^{52}$ Proponents of this method favor experimentation instead of elaborate planning, customer input over intuition, and designing in the open instead of in "stealth mode." ${ }^{53}$ The second principle is building products or services using "agile development": a model that incorporates feedback from users to quickly redesign and relaunch their innovation. ${ }^{54}$ As a result, entrepreneurs are used to being nimble, quickly

${ }^{51}$ Over-Regulated America: The Home of Laissez-Faire is Being Suffocated by Excessive and Badly Written Regulation, ECONOMIST (Feb. 18, 2012), http://www.economist.com/node/215 47789 [https://perma.cc/FE7S-ZBSX].

${ }^{52}$ Tim Raynor, Startups and the Hacker Way: The (Counter-) Cultural History of Lean Method, MEDIUM (Mar. 20, 2016), https://medium.com/@timrayner01/startups-and-thehacker-way-on-the-counter-cultural-history-of-lean-method-ce7e9b736ed1

[https://perma.cc/WC3X-HUAL] (lean startup methods, along with design thinking and agile development, are the basis of hacker culture, which has been adopted by the Silicon Valley innovation culture); see Steve Blank, Why the Lean Startup Changes Everything, HARV. BuS. REV. (May 2013), https://hbr.org/2013/05/why-the-lean-start-up-changes-everything [https://perma.cc/Q72U-X3K6] (“On the basis of what I've seen at hundreds of start-ups, at programs that teach lean principles, and at established companies that practice them, I can make a more important claim: Using lean methods across a portfolio of start-ups will result in fewer failures than using traditional methods."); see generally ERIC RIES, THE LEAN STARTUP: How TODAY'S ENTREPRENEURS USE CONTINUOUS INNOVATION TO CREATE RADICALly SUCCESSFUL BUSINESSES (2011) (describing the lean-startup method of growing a business).

${ }^{53}$ Blank, supra note 52.

${ }^{54}$ See Blank, supra note 52 ("“A]gile development eliminates wasted time and resources by developing the product iteratively and incrementally. It's the process by which start-ups create the minimum viable products they test."). The team then uses the consumers' feedback on the Minimum Viable Product to create successive versions of the product or service. Id. In each cycle, user feedback is quickly adopted and a new version is released. Id. The agile method differs from the traditional waterfall model. See Jim Bowes, Agile vs. Waterfall: Comparing Project Management Methods, MANIFESTO (July 17, 2014), https://manifesto.co.uk/agile-vs- 
addressing consumers' issues that arise with a particular version of their product, or "pivoting" to a new product when feedback indicates that the appeal of their current minimum viable product is limited.

Following the lean-startup method and the agile-development process, entrepreneurs have embraced a culture of disruption, often based on the philosophy of "ask forgiveness, not permission." was not designed to foster rule breaking, entrepreneurs have applied this attitude toward existing rules and laws. ${ }^{56}$

\section{The Clash of Two Very Different Cultures}

New technologies allow innovators to engage with prospective users early in the creative process to receive feedback while the product or service is still in development. Therefore, entrepreneurs are used to welcoming change; new feedback continually informs their understanding of user needs and preferences. ${ }^{57}$ State and federal regulatory processes, however, tend to be

waterfall-comparing-project-management-methodologies/ [https://perma.cc/XA97-YRMU]. The waterfall method is a process in which each a product moves linearly through each phase of its life cycle from design to implementation. See id. Then, the product is tested at the final stage of execution of the design. See id. Only after testing is complete is the product or service released to consumers. See id.

${ }^{55}$ See Bill Murphy, Jr., Want to Succeed in Life? Ask for Forgiveness, Not Permission, INC (Jan. 20, 2016), http://www.inc.com/bill-murphy-jr/9-words-to-live-by-its-always-better-tobeg-forgiveness-than-ask-permission.html [https://perma.cc/4BNH-ZH8S] (“[I]t's a popular mantra now, among high-performing entrepreneurs."); Neil Irwin, For Start-Ups Looking to Disrupt Regulated Industries, the New Strategy Is: Ask Forgiveness, Not Permission, N.Y. TIMES (Apr. 22, 2014), https://www.nytimes.com/2014/04/23/upshot/for-start-ups-looking-todisrupt-regulated-industries-the-new-strategy-is-ask-forgiveness-not-permission.html [https://nyti.ms/2jfudyg].

${ }^{56}$ See Mike Bishop, Breaking the Law-How Many Great Entrepreneurs Get Their Start, LINKEDIN (Sept. 22, 2015), https://www.linkedin.com/pulse/breaking-law-how-many-greatentrepreneurs-get-start-mike-bishop-jd/ [https://perma.cc/5UMC-T4WH]; see also Aarti Shahani, As Uber Expands, It Asks Cities for Forgiveness Instead of Permission, NPR (Dec. 26, 2014), https://www.npr.org/sections/alltechconsidered/2014/12/26/373087290/as-uberexpands-it-asks-cities-for-forgivness-instead-of-permission [https://perma.cc/3D4D-KAWF]

57 See Ted Ladd, The Limits of the Lean Startup Method, HARV. Bus. REV. (Apr. 2016), https://hbr.org/2016/03/the-limits-of-the-lean-startup-method [https://perma.cc/B39P-6EW6] (acknowledging the popularity of Eric Ries' lean startup method); Steve Lohr, The Rise of the Fleet-Footed Startup, N.Y. TIMES (Apr. 24, 2010), http://www.nytimes.com/2010/04/25/busi ness/25unboxed.html?dbk [https://nyti.ms/2rNjH0a] (describing Eric Ries' method: "the start- 
slow and deliberative, involving years of preliminary fact finding activities, rulemaking notices, public hearings, proposed rules, and comment periods before new rules are able to be promulgated. ${ }^{58}$

Conceptually, the ways in which platform companies' attitudes of disruption clash with traditional regulatory systems can be separated into three categories: (1) Nimble Methods versus Slow Deliberative Methods, (2) New Business Models versus Old Rules, and (3) Many Resources versus Few Resources. Following this roadmap, Part II of this article will demonstrate how the clash of culture played out in the regulatory battles of the two largest platform companies: Uber and Airbnb.

\section{Nimble Methods Versus Slow Deliberative Methods}

Entrepreneurs in the platform economy often base their businesses on the agile development process. ${ }^{59}$ Their reliance on nimble processes makes it difficult for innovators to understand and respect the drawn-out process of regulation. ${ }^{60}$ This lack of respect can make entrepreneurs disinclined to follow

up should continually experiment by tweaking its offering, seeing how the market responds and changing the product accordingly.").

${ }^{58}$ Cf. Flowchart of Public Rulemaking Process in California, supra note 45 (describing at least eight steps required to write and implement a California state regulation, including at least one and possibly two forty-five-day comment periods).

59 See, e.g., John Glover, Uber and Airbnb: The Importance of Agile Working in 2015, KAHOOTZ (June 3, 2015), http://cloud-collaboration.kahootz.com/uber-and-airbnb-theimportance-of-agile-working-in-2015 [https://perma.cc/7L8Z-HS5U] (describing how Uber, Airbnb, Alibaba and Facebook all have broken away from traditional business models and used agile development methods to become successful).

${ }^{60}$ Cf. Ingrid Lunden, Uber's Travis Kalanick on Regulators: You Have to Grit Your Teeth, Be a Warrior, or Do Something Less Disruptive, TECHCRUNCH (Sept. 12, 2012), https://techcrunch.com/2012/09/12/ubers-travis-kalanick-on-regulators-you-have-to-grit-yourteeth-be-a-warrior-or-do-something-less-disruptive/

[https://perma.cc/ZK2W-CMS9] (mentioning the length of the decision-making process a one of three ways that regulators get things wrong when regulating innovative companies); Matt McFarland, America's Clumsy Regulation of Drones Stirs Up Frustration, Confusion, WASH. POST (Dec. 9, 2010), https://www.washingtonpost.com/news/innovations/wp/2014/12/09/americas-clumsy-

regulation-of-drones-stirs-up-frustration-confusion/ [https://perma.cc/X8TV-TCVH] (describing a drone operator as frustrated by regulators that don't keep up with a rapidly developing field); Howard Beales, et al., Government Regulation: The Good, the Bad, \& the Ugly, Reg. Transparency Project Federalist Soc. (June 12, 2017), https://regproject.org/paper/government-regulation-the-good-the-bad-the-ugly/

[https://perma.cc/38XE-BQF7] ("[U]nlike ecosystems and interactions in non-government 
the existing rules. ${ }^{61}$ Ironically, however, it is specifically what entrepreneurs disrespect about regulation, the existence of regulatory capture and the slow deliberative methods of regulators, that fosters the consumer demand or "pain points" that an innovative company needs to succeed. ${ }^{62}$

spheres, where individuals and organizations are constantly learning from past experience and updating their behavior accordingly, the regulatory sphere has no feedback loop.").

${ }^{61}$ See Mike Isaac, How Uber Deceives the Authorities Worldwide, N.Y. TIMES (Mar. 3, 2017), https://www.nytimes.com/2017/03/03/technology/uber-greyball-program-evadeauthorities.html [https://nyti.ms/2lngDck] (noting that "Uber has long flouted laws and regulations to gain an edge"). Some academics have adopted the argument that regulations should not apply to startups. See Viktor Mayer-Schönberger, E-Commerce, Entrepreneurship and the Law: Reassessing a Relationship, in THE EMERGENCE OF ENTREPRENEURSHIP AND POLICY: GOVERnANCE, STARTUPS AND GROWTH 199 (David M. Hart, ed., 2003) (writing that for entrepreneurial companies, "no regulation seems the best of all options"); Arun Sundararajan, Why the Government Doesn't Need to Regulate the Sharing Economy, WIRED (Oct. 22, 2010), https://www.wired.com/2012/10/from-airbnb-to-coursera-why-thegovernment-shouldnt-regulate-the-sharing-economy/ [https://perma.cc/V249-ZVSQ] (arguing that rating systems on platforms replace the need for regulation).

62 Jeffrey Carter, What's a Pain Point?, PoINTS AND FIgures (Apr. 27, 2012), http://pointsandfigures.com/2012/04/27/whats-a-pain-point/ [https://perma.cc/7CBZ-HLR5] (stating that "a pain point is a problem, real or perceived. Entrepreneurs create opportunities for themselves by creating solutions to those pain points. Solutions create value for everyone."). The larger the pain point, the more consumers will be benefited by the solution. For example, New York has long restricted the number of medallions for taxi drivers. See Lawrence Van Gelder, Medallion Limits Stem from the 30s, N.Y. TIMES (May 11, 1996), http://www.nytimes.com/1996/05/11/nyregion/medallion-limits-stem-from-the-30-s.html [https://nyti.ms/2jhBePl]. Even in 2016, there were only 13,347 medallions. See N.Y. CITY TAXI AND LIMOUSINE COMM'N, 2016 ANNUAL REPORT 2 http://www.nyc.gov/html/tlc/downl oads/pdf/annual_report_2016.pdf [https://perma.cc/LS44-VGTW]. By early 2017, cars driven for Uber and Lyft exceeded the number of New York City yellow cabs by 4 to 1 . Rachel Sugar, Uber and Lyft Cars Now Outnumber Yellow Cabs in NYC 4 to 1, CURBED (Jan. 17, 2017), https://ny.curbed.com/2017/1/17/14296892/yellow-taxi-nyc-uber-lyft-via-numbers [https://perma.cc/MK3M-C243]. Cf. Jordan Chittley, Taxi Industry Losing War to Uber Because of Customer Service, Not Technology, Globe \& MAIL (Dec. 9, 2015), https://beta.theglobeandmail.com/globe-drive/culture/commentary/taxi-industry-losing-warto-uber-because-of-customer-service-nottechnology/article27656590/?ref=http://www.theglobeandmail.com\& [https://perma.cc/BK4A-JKRK] (noting that Uber and other ridesharing companies took advantage of this situation by increasing the availability of rides as well as creating ondemand access to their services). 


\section{New Business Models versus Old Rules}

While previously it has been possible to find a shared ride or a vacation home to rent on community bulletin boards or local newsletters, platform companies have greatly expanded the number of these transactions and monetized them by taking a fee when a transaction results between users and providers on their platform. ${ }^{63} \mathrm{New}$ technologies allow the founders of platform companies to directly connect the users of services to those who can provide them. As a result, platform companies do not own assets fundamental to the services they provide. ${ }^{64}$

Existing regulations for taxi companies and hotels were written predominantly when taxi companies and hotels owned the cars and rooms, respectively, that they provided. The regulations therefore include rules about the condition, hygiene, and use of those assets. ${ }^{65}$ Because platform companies do not own these fundamental assets, founders of these companies argue that the regulations written for incumbent companies do not apply to them. ${ }^{66}$ This argument enables platform companies to continue to operate after regulators

${ }^{63}$ See Martin Kenney \& John Zysman, The Rise of the Platform Economy, 32 IsSUES SCI. \& TECH. $\quad 3$ (2016) http://issues.org/32-3/the-rise-of-the-platform-economy/ [https://perma.cc/F6G9-26EZ] (noting that Uber, Airbnb, and Facebook are not based on "sharing"; rather, they monetize human effort and consumer assets). One characteristic of making these connections in the traditional way was that the user often knew the provider or they were members of the same community and were incentivized to treat each other fairly to preserve their reputations in the community. The platform companies and their supporters argue that they have replicated this trust through their ratings systems. See Arun Sundararajan, supra note 61 ("In the sharing economy, reputation serves as the digital institution that protects buyers and prevents the market failure that economists and policy makers worry about.") (emphasis added); but see Armitage, supra note 30, at 29-31 (ratings systems do not function effectively to protect consumers).

${ }^{64}$ Geoffrey A. Fowler \& Ted Mann, Taxi Apps Face Bumpy Road, Wall ST. J. (Oct. 28, 2012), https://www.wsj.com/articles/SB10001424052970204005004578082630070372690 ("Uber CEO Travis Kalanick says regulators misunderstand his company because, unlike cab or limo companies, Uber doesn't own cars or employ drivers.").

${ }^{65}$ See CAL. CodE REgs. tit. 25, $\S \S 32-46$ (2017) (hotel owners are legally required to maintain the safety and cleanliness of their properties at all times); New York, N.Y., Rules of New York City. ch 35. §§ 51-83 (legal requirements for taxicab and limousine safety in New York City).

${ }^{66}$ See Lunden, supra note 60 (stating that regulators put the brakes on in cases where they haven't actually established rules and quoting Travis Kalanick saying that "[a] regulator is supposed to create and enforce a standard. If they don't have a standard, that doesn't make it illegal.”). 
attempt to ban their operations. Being able to argue that regulations do not apply to them is critical to the survival of these innovative companies. ${ }^{67}$

Platform companies grow quickly in part because, if they have successfully solved a major "pain point" for consumers, many people want to use their services. The large user base that results from this demand provides these companies with leverage over regulators in three powerful ways. First, users can be easily mobilized to create a groundswell of public opposition if regulators threaten to restrict the availability of their services. ${ }^{88}$ Second, millions of users indicate that the business has traction, which attracts additional investments from venture capitalists. With these additional funds, platform companies can lobby the government, afford expensive litigation, and finance campaigns to influence public opinion. ${ }^{69}$ Third, platform technology enables companies to amass large amounts of data. This data could be extremely useful to city and state officials as they plan for the future and

${ }^{67}$ Platform companies that have attempted to comply with regulators from the time they launch claim they have been put out of business by the process. See Susie Cagle, How a Startup That Wouldn't Break the Rules Was Forced to Fail, PAC. STANDARD MAG. (Jan. 27, 2015), https://psmag.com/how-a-start-up-that-wouldn-t-break-the-rules-was-forced-to-fail657d60b71ef0\#.7flvajjmb [https://perma.cc/Q6GV-KUK7].

${ }^{68}$ See Derek Thompson, How Uber's Taxi App is Changing Cities, ATLANTIC (Nov. 23, 2013), http://www.theatlantic.com/business/archive/2013/11/how-ubers-taxi-app-is-changingcities/281451/ [https://perma.cc/YDY9-73RU] (describing a late-night social media campaign by Uber to defeat a proposed Congressional amendment). Airbnb also employed this strategy to defeat Proposition F in San Francisco in 2015. See Carolyn Said, Prop. F: S.F. Voters Reject Measure to Restrict Airbnb Rentals, S.F. GATE (Nov. 4, 2015), http://www.sfgate.com/bayarea/article/Prop-F-Measure-to-restrict-Airbnb-rentals-

6609176.php [https://perma.cc/JRH6-BSVX].

${ }^{69}$ In 2016, Airbnb's revenue was estimated at nearly $\$ 1.7$ billion and the company was valued at $\$ 30$ billion. See Tessa Love, Airbnb's Revenue Soars 89 Percent, S.F. BuS. TIMES (Sept. 1, 2016), http://www.bizjournals.com/sanfrancisco/news/2016/09/01/airbnbs-revenue-soarscompared-to-hotels.html [https://perma.cc/U4WW-E3D9]. During the first half of 2015, Uber's revenue exceeded $\$ 650$ million. Brian Solomon, Leaked: Uber's Financials Show Huge Growth, Even Bigger Losses, FORBES (Jan. 12, 2016), http://www.forbes.com/sites/briansolomon/2016/01/12/leaked-ubers-financials-show-hugegrowth-even-bigger-losses/\#65257b3d5c99 [https://perma.cc/ST39-MJTR]. Because Uber's revenue model suggested traction, even though the company had lost money in 2015, Uber was valued at $\$ 62.5$ billion in a 2016 funding round. See Eric Newcomer \& Glen Carey, Uber Receives \$3.5 Billion Investment from Saudi Wealth Fund, BLOOMBERG (June 1, 2016), https://www.bloomberg.com/news/articles/2016-06-01/uber-receives-3-5-billion-investmentfrom-saudi-wealth-fund [https://perma.cc/Q2JQ-9LQJ]. 
assess the impact of the platform companies on their jurisdictions. ${ }^{70}$ Ownership of this data provides companies with a valuable bargaining chip when negotiating with local officials.

Traditional regulations can be difficult to apply to the new business models of the platform economy companies for yet another reason. Most rules are written for commercial enterprises and are based on two assumptions about the targeted businesses: first, they will possess a certain level of knowledge and sophistication about regulations and the regulatory process; and second, they will have the resources necessary to comply with complex regulations. The business model of the platform companies, however, permits individuals to earn income from activities previously available only to employees. ${ }^{71}$ One of the founders of Airbnb, Brian Chesky, acknowledged this point: "There were laws created for businesses, and there were laws for people. What the sharing economy did was create a third category: people as businesses." 72 The sorts of rules that are appropriate for business entities may not be appropriate for people who are providing the service as individuals using their personally-owned assets. These individuals often don't have much knowledge of the rules that apply to them now that they are, according to regulators, a commercial operation. ${ }^{73}$

\footnotetext{
${ }^{70}$ See STONE, supra note 3, at 121 (noting how Uber had more access to city-wide traffic and transit data than any other company). See also Carolyn Said, Airbnb, HomeAway Settle SF Suit, Agree to Register All Hosts, SFGATE (May 1, 2017, 7:17 PM), http://www.sfgate.com/business/article/Airbnb-settles-SF-suit-agrees-to-register-all-

11112109.php (mentioning how vital data was to Airbnb's cease-fire with San Francisco) [https://perma.cc/TB3M-RR27].

71 Platform companies do not follow the traditional relationship between employer and employee. Instead, those who provide services on behalf of the companies, e.g., Uber drivers and Airbnb renters, are classified as independent contractors. This very important discussion is, however, outside the scope of this essay. For an examination of the issues, see generally Benjamin Means \& Joseph Seiner, Navigating the Uber Economy, 49 U.C. DAVIS L. REV. $1511 \quad$ (2016), https://papers.ssrn.com/sol3/papers.cfm?abstract_id=2663350 [https://perma.cc/VE5H-SMQ3]; see also Keith Cunningham-Parmeter, From Amazon to Uber: Defining Employment in the Modern Economy, 96 B.U. L. Rev. 1673 (Apr. 13, 2016), https://papers.ssrn.com/sol3/papers.cfm?abstract_id=2761577 [https://perma.cc/URX2JUQR].

${ }^{72}$ See Andy Kessler, Brian Chesky: The 'Sharing Economy' and Its Enemies, WaLl ST. J. (Jan. 17, 2014, 7:00 PM), http://www.wsj.com/articles/SB10001424052702304049704579321 001856708992.

${ }^{73}$ There is evidence that some property owners are using Airbnb's platform to rent out multiple units, thereby operating true commercial enterprises. See, e.g., Chabeli Herrera,
} 
In sum, the new business models of platform companies cause struggles with regulators in three ways: first, they are able to argue plausibly that traditional regulations do not apply and thus continue to operate in the face of bans and prohibitive fees; second, they are able to quickly amass large consumer bases that supply additional pressure on regulators; and third, the actual provider of the commercial service, the owner of the asset used to supply the service is often an unsophisticated micro-entrepreneur. Thus it is not a simple matter for regulators to know the best ways to write rules that govern these innovative companies. For all these reasons, in a traditional regulatory system, successful platform companies have become "too big to regulate. ${ }^{, 74}$

Airbnb and Hoteliers Battle Over Role, Regulations for Home-Sharing in Miami, MIAMI HERALD (May 25, 2016), http://www.miamiherald.com/news/business/tourismcruises/article79673612.html [https://perma.cc/VMD9-8R32] (“Airbnb operators who offer multiple units on the online service drove 62 percent of Airbnb's regional revenue - about $\$ 76$ million.”). Any regulations formulated to apply to Airbnb hosts should attempt to distinguish between true home-sharing hosts and property owners attempting to run commercial enterprises. There have also been complaints that fleet operators are using Uber's platform to run a commercial ride-sharing business. See Ashleigh Davis, How Your Young Uber Driver Affords Such a Nice Car: Meet the People Renting Out Fleets of Cars to Drivers on the Ride Sharing App, DAILY MAIL (Apr. 22, 2016), http://www.dailymail.co.uk/news/article-3553498/Meet-people-renting-fleets-cars-Uberdrivers-ride-sharing-app.html [https://perma.cc/Y5XD-3B78].

${ }^{74}$ This term was used in an op-ed in the New York Times in 2014 to complain that the banks, which were "too big to fail" in 2008 and hence bailed out by the government, were being treated as "too big to regulate" six years later by the Federal Reserve as it once again refused to apply the stricter capital and leverage requirements included in the Dodd-Frank financial reform bill passed by Congress as part of the bail-out agreement. The Editorial Board, Too Big to Regulate, N.Y. TIMES (Aug. 9, 2014), http://www.nytimes.com/2014/08/10/opinion/su nday/too-big-to-regulate.html [https://nyti.ms/2jGyZQK]. It seems that Kalanick himself was aware of the concept of developing a product that has become too big to regulate. $C f$. Christine Laogoria-Chafkin, Resistance is Futile, INC (July-Aug. 2013), https://www.inc.com/magazine/201307/christine-lagorio/uber-the-car-service-explosivegrowth.html [https://perma.cc/ZK5T-X55L] (quoting Travis Kalanick) ("Uber riders are the most affluent, influential people in their cities. When we get to a critical mass, it becomes impossible to shut us down."). 


\section{Access to Resources versus Limited Resources}

Some platform-economy companies have the benefit of receiving substantial funding from private investors. ${ }^{75}$ With this level of funding, platform companies can engage in costly battles with regulators by utilizing lobbyists to influence state and municipal officials, and by employing lawyers to defend against court actions. ${ }^{76}$

The regulators who challenge these companies often have limited resources. In recent battles, most of these regulators have been state and municipal-rather than federal-authorities. ${ }^{77}$ As compared to federal regulators, these local officials do not have the staff or resources to create or oversee the extensive regulations that would be needed to effectively control the platform-economy companies. ${ }^{78}$ Moreover, sometimes the platformeconomy companies control the data needed to enforce regulations and decline to share this data with regulators. ${ }^{79}$

75 See Chris Meyers, Decoding Uber's Proposed \$50B Valuation, ForBes (May 13, 2015), https://www.forbes.com/sites/chrismyers/2015/05/13/decoding-ubers-50-billion-valuationand-what-it-means-for-you/\#57a5f2ee785a [https://perma.cc/TM3B-8FL6] (noting that in May 2015, Uber was the "world's most highly capitalized startup"). In October 2017, Uber was valued at $\$ 69$ billion. See Alexei Oreskovic, Uber will IPO by 2019 and let Softbank Buy a Huge Stake, Following a Big Board Meeting, BuS. INSIDER, (Oct. 3, 2017), http://www.businessinsider.com/uber-board-says-it-approved-equality-among-shareholdersand-to-move-forward-with-softbank-deal-2017-10?r=UK\&IR=T [https://perma.cc/8Q6N4DTG]. In addition, some of the founders had funds of their own from prior successful startups they had sold. See STONE, supra note 3, at 119 (discussing Travis Kalanick's payout from selling a business he founded, Red Swoosh).

${ }^{76}$ See, e.g., Rosalind Helderman, Uber Pressures Regulators by Mobilizing Riders and Hiring Vast Lobbying Network, WASH. POST (Dec. 13, 2014), https://www.washingtonpost.com/politics/uber-pressures-regulators-by-mobilizing-ridersand-hiring-vast-lobbying-network/2014/12/13/3f4395c6-7f2a-11e4-9f38-

95a187e4c1f7_story.html [https://perma.cc/A4FW-DTMJ].

${ }_{77}$ The industries in which most platform companies operate, such as the taxi and hotel industries, have traditionally been regulated by the jurisdiction in which they operate, and not by federal agencies. See Eric Posner, Why Uber Should—and Will-Be Regulated, SLATE (Jan. 5, 2015), http://www.slate.com/articles/news_and_politics/view_from_chicago/2015/01/ uber_surge_pricing_federal_regulation_over_taxis_and_car_ride_services.html

[https://perma.cc/V6TN-2QDF].

${ }^{78}$ For a list of the changes that would be needed to make existing regulations work with platform companies' business models, see Miller, supra note 50.

${ }^{79}$ See Annie Karni, Uber Loses TLC Appeal to Turn Over Trip Data, N.Y. DAILY NEWS (Jan. 22, 2015), http://www.nydailynews.com/news/politics/uber-loses-tlc-deal-turn-trip-data- 


\section{Conclusion}

For all of the reasons discussed above, attempts to regulate platform companies have not gone smoothly. Much of the tension between the entrepreneurs and the regulators stems from the platform companies' innovative business models that are not obviously within the scope of traditional regulations. Some of the tension also stems from a clash of cultures: the iterative, fast-paced world of disruption does not mesh easily with the deliberative, slow-moving process of traditional rulemaking. In Part II, we will describe real-life examples of this tension as we delve into the details of the struggles of California and New York authorities to regulate Uber and Airbnb.

\section{REACTIVE REGULATORS AND UNCOOPERATIVE COMPANIES}

In the first two decades of the twenty-first century, technological innovation has allowed many nascent companies to provide traditional services like transportation and lodging to customers in new ways. ${ }^{80}$ As

article-1.2087718 [https://perma.cc/J6BH-LDEV]; Murray Cox \& Tom Slee, How Airbnb's Data Hid the Facts in New York City, INSIDE AIRBNB (Feb. 10, 2016), http://insideairbnb.com/how-airbnb-hid-the-facts-in-nyc/ (detailing how Airbnb removed hundreds of listings by hosts with multiple properties in New York before providing data to NY officials) [https://perma.cc/KJ2T-Q75L]. Even when complying with regulations, Uber and Airbnb do not provide fine-grained information to regulators with respect to tax collection and background checks. See Emily Badger, What Happens When Uber and Airbnb Become Their Own Regulators, WASH. POST (Feb. 4, 2015), https://www.washingtonpost.com/news/wonk/wp/2015/02/04/what-happens-when-uber-andairbnb-become-their-own-regulators/ [https://perma.cc/R64Q-NG2Z]; see also Kia Kokalitcheva, Most San Francisco Airbnb Hosts Shirk Regulations, Report Finds, FORTUNE (Apr. 8, 2016), http://fortune.com/2016/04/08/airbnb-hosts-not-compliant-san-francisco/ [https://perma.cc/6PHS-ULLP]; Andrew J. Hawkins, Uber Fined \$7.6 Million in California for Failure to Report Driver Data, VERGE (Jan. 14, 2016), http://www.theverge.com/2016/1/14/10772412/uber-fine-california-utility-driver-data [https://perma.cc/7H32-ED3D].

${ }^{80}$ The platform economy goes beyond Uber and Airbnb, with other companies providing services such as car sharing, valet parking, and food delivery. Founded in 2014, Getaround is a car-sharing service that aims to decrease car ownership in cities. See Carolyn Said, City CarShare Hands Over On-Demand Auto Rentals to Getaround, S.F. Chronicle (Nov. 10, 2016), http://www.sfchronicle.com/business/article/City-CarShare-hands-over-on-demandauto-rentals-10605179.php [https://perma.cc/79QY-PUSR] (quoting Sam Zaid, Getaround CEO: "We see a true long-term shift in how consumers will access transportation in the 
established in Part I, there are inherent cultural and contextual reasons for regulators and platform companies to clash. ${ }^{81} \mathrm{~A}$ command-type regulatory system has few, if any, mechanisms to resolve or ameliorate the tensions. ${ }^{82} \mathrm{~A}$ regulator's toolkit primarily provides punitive options, such as fines and cease-and-desist orders, to enforce regulations. ${ }^{83}$

The struggle between platform companies and regulators often begins with a standard reactive response from the regulators after the company has already begun operating in the city. This pattern is borne out in the Uber and the Airbnb sagas in both San Francisco and New York. In neither city did regulators reach out with an offer of collaboration or an attempt to call a company in for discussions. Instead regulators drew a line in the sand by

future, moving away from ownership toward access"). Luxe Valet takes those who are hesitant to drive in cities due to lack of parking, and connects them with on-demand valets. See Sarah Tilton, San Francisco Entrepreneur Aims to Make Parking 'a Delight' with OnDemand Valet, FORBES (Oct. 23, 2014), https://www.forbes.com/sites/sarahtilton/2014/10/23/ san-francisco-entrepreneur-aims-to-make-parking-a-delight-with-on-demand-

valet/\#62ae7ae04407 [https://perma.cc/BZB4-D7JX]. Postmates provides both take-out food and grocery-store delivery to busy city dwellers. See Ryan Lawler, On-Demand Delivery Startup Postmates Raises \$16 Million from Spark Capital, TECHCRUNCH (Feb. 18, 2014), https://techcrunch.com/2014/02/18/postmates-16m-spark-capital/ [https://perma.cc/7KJFSUQ8].

${ }^{81}$ Although beyond the scope of this article, these clashes are likely with any new company utilizing agile development models to produce products quickly and bring them to market with an unproven beta model. Pressure is already mounting on regulators to provide legislative guidelines and limits to autonomous car companies as the technology becomes more and more accessible for consumers. Mercedes Benz, for example, has pledged to have a fully autonomous car available for the market by 2021. See Nathan Bomey \& Thomas Zambito, Regulators Scramble to Stay Ahead of Self-Driving Cars, USA TODAY (June 25, 2017), https://www.usatoday.com/story/money/cars/2017/06/25/regulators-scramble-stayahead-self-driving-cars/100963150/ [https://perma.cc/52EC-FRLM].

${ }^{82}$ Samuel Stayley, Taxi Regulation and the Failures of Progressivism, Found. ECON. EdU. (Jan. 4, 2012), https://fee.org/articles/taxi-regulation-and-the-failures-of-progressivism/ [https://perma.cc/7R2H-EKYE] (detailing the specificity and commands of taxi regulation: "Taxi regulations and codes fix prices by law, mandate the way fares are collected (meters), dictate hours of operation (24-hour dispatch service), regulate financial operations (by requiring financial reporting), promote public safety (vehicle inspections), set standards for language fluency and driver competence (tests), and include dozens of other regulations.").

83 Christopher Carringan \& Elise Harrington, Choices in Regulatory Program DESIGN AND ENFORCEMENT 28-46 (2015), https://www.law.upenn.edu/live/files/4706carriganharrington-ppr-researchpaper062015pdf [https://perma.cc/Q2FZ-4WRT] (detailing different kinds of regulation and enforcement and describing two for command regulations: discretionary punishment and nondiscretionary punishment). 
issuing cease-and-desist letters or enacting restrictive laws. ${ }^{84}$ Uber and Airbnb, both bolstered by the huge consumer demand for their innovative services, ${ }^{85}$ fought back. ${ }^{86}$ As the following sections will demonstrate, the resulting disputes created escalating costs and negative publicity for both sides. ${ }^{87}$ The battle began, however, with harsh and punitive responses from regulators that forced the young companies to adopt equally combative measures to keep the regulators at bay.

${ }^{84}$ See Lora Kolodny, UberCab Ordered to Cease And Desist, TeChCRUnCH (Oct. 24, 2010), https://techcrunch.com/2010/10/24/ubercab-ordered-to-cease-and-desist/

[https://perma.cc/8D7X-HZRD]; Jessica Dailey, An Introduction to New York's Short Term Rental Laws, CURBED N.Y.C. (Mar. 25, 2013), https://ny.curbed.com/2013/3/25/10260752 [perma.cc/AN2L-MTFN] (2011 New York state law prohibits rentals of less than 30 days unless family member present or unit zoned as hotel or hostel); see also Joshua D. Wright, Chairman, Fed. Trade Comm'n, Remarks at Clemson University: Regulation in High-Tech Markets: Public Choice, Regulatory Capture, and the FTC (Apr. 2, 2015), https://www.ftc.gov/system/files/documents/public_statements/634631/150402clemson.pdf

[https://perma.cc/VFU6-CD6G] (in the taxi industry, "regulators have responded by doubling down on competition-reducing regulations rather than by allowing new disruptive competition to flourish").

${ }^{85}$ See Alexis C. Madrigal, The Rise of the One-Room Hotel, AtLantiC (Nov. 11, 2010), https://www.theatlantic.com/technology/archive/2010/11/the-rise-of-the-one-room-

hotel/66439/ [https://perma.cc/NC3W-XAZD] (noting that Airbnb reported booking 560,000 rooms in the six months prior to the article); see also Michael Arrington, Huge Vote of Confidence: Uber Raises \$11 Million From Benchmark Capital, TeCHCRUNCH (Feb. 14, 2011), https://techcrunch.com/2011/02/14/huge-vote-of-confidence-uber-raises-11-millionfrom-benchmark-capital/ [https://perma.cc/C9MK-8GV4] (noting that between summer 2010 and February 2011 Uber had tens of thousands of paid rides in San Francisco alone).

${ }^{86}$ Cf. Nolan Hicks \& Ben Ware, Uber, Lyft Spending Now at \$8.1 Million in Prop 1. Race, MySTATESMAN (Apr. 29, 2016), http://www.mystatesman.com/news/local-govt-politics/uber-lyft-spending-now-million-prop-race/NJUedjBB9NJs4hficHDsxN/

[https://perma.cc/8M7X-VDUE] (demonstrating Uber's effort to create favorable regulations); Ben Popper, Uber Can't Be Stopped, So What Happens Next? VERGE (July 27, 2015), https://www.theverge.com/2015/7/27/9035731/future-of-uber-regulation-illegal-

violations [https://perma.cc/P448-TQHL] ("We should be wary of Uber, which has so far flouted almost all attempts at regulation."); Tim Redmond, Why is SF Tolerating Airbnb's Bad Behavior?, 48HILLS.ORG (Oct. 6, 2016), http://48hills.org/2016/10/06/sf-toleratingairbnbs-bad-behavior/ [https://perma.cc/A46W-PUX9] (claiming the city's Airbnb regulations are a total sham and the city cannot or will not control illegal rentals).

${ }^{87}$ See infra text accompanying notes $117-118$. 


\section{A. Uber}

Part I described causes of tensions between regulators and platform companies: nimble methods versus methodical methods; new business models versus old rules and tools; and many resources versus few resources. These three causes of tension are demonstrated in many of the interactions between Uber and regulators in various localities. Uber was at first conciliatory towards regulators, offering to educate regulators about why its business model fell outside the categories of existing rules. As regulators continued to issue punitive rules and penalties, however, Uber became more confrontational and the fight escalated. While Uber eventually prevailed against regulators in most cities around the world, the position it ultimately embraced as a result - that it is not bound by existing rules - became, to the company's eventual detriment, a company mantra in all aspects of its operations and culture. ${ }^{88}$

\section{Early Interactions with Regulators}

Uber was first available to the public to book rides in San Francisco in July 2010 as UberCab. ${ }^{89}$ Despite its name, the company only provided a way to book an on-demand ride in a luxury vehicle with a licensed driver, thereby taking much of the hassle out of having to book and pay for a private ride. ${ }^{90}$ Within three months, the California Public Utilities Commission (CPUC) and the San Francisco Metropolitan Transit Authority (SFMTA) issued Uber a cease-and-desist order for operating a taxi company without a license. ${ }^{91}$ In response, Uber promptly dropped "Cab" from its name and continued to

${ }^{88}$ See Dan Hill, Uber Doesn't Have a PR Problem, It Has a Culture Problem, NewsweEK, (Apr. 19, 2017), http://www.newsweek.com/uber-culture-problem-pr-585511 [https://perma.cc/DLR8-C4U3] ("[t]hose kinds of ongoing and protracted legal and regulatory battles undoubtedly contribute to why the company's posture continues to be hyperaggressive").

${ }^{89}$ See Leena Rao, UberCab Takes the Hassle Out of Booking a Car Service, TECHCRUNCH (July 5, 2010), https://techcrunch.com/2010/07/05/ubercab-takes-the-hassle-out-of-booking-acar-service/ [https://perma.cc/BEA2-NQZ3] (describing UberCab as a new service when the article was written in 2010).

${ }^{90} I d$. (describing the service as convenient and asserting that passengers "receiv[e] better service, a nice black limo and an on-demand solution").

${ }^{91}$ See Kolodny, supra note 84. 
operate its black car service. ${ }^{92}$ The regulators meanwhile continued to insist that Uber needed to register with the state, but Uber, which had just raised a round of funding for $\$ 1.25$ million, ${ }^{93}$ had the resources to hire lawyers. These lawyers ultimately convinced the CPUC that Uber was not a taxi or limousine service, but rather a referral service connecting those who wanted a ride to those who could provide that ride-just as Expedia or Orbitz were referral services that connected travelers to airlines. ${ }^{94}$ Uber also posted a conciliatory statement on its website from then-CEO Ryan Graves. ${ }^{95}$ By late 2010, the regulators agreed and issued a ruling allowing Uber to operate without registering with the state. ${ }^{96}$

Uber, for the moment at peace with California regulators, took its black car service to New York in May of 2011. ${ }^{97}$ Because that business model (a limousine company using already licensed drivers) fit neatly within its existing rules, the Taxi and Limousine Commission (TLC) initially gave Uber permission to operate. ${ }^{98}$ When Uber pivoted and began competing with the city's taxi space in 2012, however, interactions with regulators became more heated. Even though UberTaxi was designed to use already licensed taxi drivers, Uber itself did not own medallions and wasn't a licensed taxi company. The TLC, using the tools available to it, ${ }^{99}$ issued rules that created heavy fines and a possible loss of commercial licenses for drivers that

\footnotetext{
${ }^{92}$ Laura Kolodny, Ubercab, Now Just Uber, Shares Cease and Desist Orders, TECHCRUNCH (Oct. 25, 2010), https://techcrunch.com/2010/10/25/ubercab-now-just-uber-shares-cease-anddesist-orders/ [https://perma.cc/9B7C-63W6].

${ }^{93}$ See Uber Funding Rounds, CRUNCHBASE, https://www.crunchbase.com/organization/uber/f unding_rounds/funding_rounds_list [https://perma.cc/XBD5-BPNZ] (indicating \$1.25 million was raised on October 10, 2010).

${ }^{94}$ See STONE, supra note 3, at 122.

${ }^{95}$ See Kolodny, supra note 84 (explaining that Graves indicated that Uber was "happy to help educate the regulatory bodies on this new generation of technology and work closely with both agencies to ensure compliance.").

${ }^{96}$ See STONE, supra note 3, at 122.

97 Uber NYC Has Launched, UBER (May 4, 2011), https://www.uber.com/blog/new-yorkcity/uber-nyc-launches-service/ [https://perma.cc/ZW4F-JE9M].

${ }^{98}$ Wortham, supra note 5.

${ }^{99}$ The Taxi and Limousine Commission (TLC) of New York City has the authority to regulate and license all for-hire vehicles in New York City. See N.Y.C. Taxi and Limo Comm'n, supra note 10. Each of its rules contains specific designations of the penalty for non-compliance (most often a fine for operating without meeting the required licensing criteria). See, e.g., 35 R.C.N.Y. § 78-02, (2017), http://www.nyc.gov/html/tlc/downloads/pdf/rule_book_current_ch apter_78.pdf [https://perma.cc/D259-V5BM].
} 
accepted rides through the Uber app. ${ }^{100}$ Uber quietly withdrew its taxi service, but within a few months the TLC decided to allow a pilot program in Manhattan. Around this time, Uber closed a Series B round for \$37 million. ${ }^{101}$ Although there are no public records available to indicate exactly how Uber used its financial resources, ${ }^{102}$ it is quite possible that Uber utilized lobbyists to try to convince TLC commissioners to change their minds. ${ }^{103}$ In any event, TLC commissioners were soon stating publicly that e-hailing apps were inevitable. ${ }^{104}$ In late April 2013, UberTaxi was granted permission to operate in New York City. ${ }^{105}$ By early 2017, Uber had become a major player in the city. ${ }^{106}$ However, until quite recently, Uber was banned in all other parts of New York state. ${ }^{107}$ Existing taxi companies lobbied their state legislators hard

${ }^{100}$ Adrianne Jeffries, Uber Quietly Shutting Down Taxis in New York After Fight with
Regulators (Update: $\quad$ Uber Confirmed), VERGE (Oct. 16, 2012), https://www.theverge.com/2012/10/16/3451108/uber-taxi-pulls-out-new-york-tlc [https://perma.cc/EU3Z-HVXB].

${ }^{101}$ See Uber Funding Rounds, CRUNCHBASE, https://www.crunchbase.com/organization/uber/ funding_rounds/funding_rounds_list [https://perma.cc/B6C7-G3DA] $(\$ 37,000,000$ Series B round closed Dec 11, 2012).

102 By 2014, it became public knowledge that Uber had employed an army of lawyers and lobbyists in different cities throughout the country. See T.C. Sottek, Uber Has an Army of at Least 161 Lobbyists and They're Crushing Regulators, VERGE (Dec. 14, 2014, 2:55 PM), https://www.theverge.com/2014/12/14/7390395/uber-lobbying-steamroller

[https://perma.cc/CR4Y-VAK2].

${ }^{103}$ See Rosalind Helderman, supra note 76 (noting that since 2012, Uber has hired private lobbyists in at least fifty U.S. cities and states).

${ }^{104}$ Adrianne Jeffries, NYC Regulators Approve Limited Pilot Program for Taxi Hailing Apps Like Uber, VERGE (Dec. 13, 2012) https://www.theverge.com/2012/12/13/3762504/taxi-ehail-tlc-nyc-vote-uber-hailo [https://perma.cc/7GXX-8BC5] (quoting TLC Chairman David Yasky).

${ }^{105}$ Adrianne Jeffries, After Long Battle, Uber Becomes First Taxi App to Get Approved in New York City, VERGE (Apr. 26, 2013) https://www.theverge.com/2013/4/26/4271490/uberbecomes-first-taxi-app-to-get-approved-in-new-york-city [https://perma.cc/E87W-HB4L]. Skirmishes continue between the ride-sharing companies and the TLC. See, e.g., Dan Ravoli, Uber and For-Hire Car Companies Unite to Fight TLC Wheelchair Plan, N.Y. DAILY NewS (Sept. 29, 2017), http://www.nydailynews.com/new-york/uber-for-hire-car-companies-unitefight-tlc-wheelchair-plan-article-1.3529233 [https://perma.cc/D34Y-S4K6].

${ }^{106} \mathrm{See} \mathrm{Hu}$, supra note 9 (noting that Uber, "the deep-pocketed newcomer[,] has become the behemoth" in the ride-hailing market in NYC).

${ }^{107}$ See Patrick Lohmann, Upstate NY's Long Wait for Uber and Lyft Ending, What You Need to Know, NYUPSTATE (June 26, 2017, 12:15 PM), http://www.newyorkupstate.com/news/201 7/06/upstate_nys_long_wait_for_uber_and_lyft_ending_what_you_need_to_know.html 
to keep Uber out of their markets. ${ }^{108}$ Demonstrating the impact of regulatory capture, those regulators refused to change existing rules despite growing consumer demand for ridesharing services. ${ }^{109}$

\section{Uber Hardens its Positions as Regulatory Battles Continue}

By mid-2013, Uber was operating in San Francisco, Seattle, Los Angeles, Boston, Chicago, Washington, DC, New York City, and expanding internationally. ${ }^{110}$ In each locale, Uber confronted regulatory challenges, including large fines and outright bans. ${ }^{111}$ Perhaps as a result of all these challenges, Uber's public stance changed from the conciliatory language of Ryan Graves' blog post ${ }^{12}$ to the position that successful, innovative

[https://perma.cc/EB23-K42K] (Uber became "a political football in budget negotiations in recent years" in the State Assembly).

${ }^{108}$ See Luz Lazo, Cab Companies Unite Against Uber and Other Ride-Share Services, WASH. Post (Aug. 10, 2014), https://www.washingtonpost.com/local/trafficandcommuting/cabcompanies-unite-against-uber-and-other-ride-share-services/2014/08/10/11b23d52-1e3f-11e482f9-2cd6fa8da5c4_story.html?utm_term=.0cb6b7622211 [https://perma.cc/JXT6-6WAZ]; $c f$. Ben Carnes, New York Is Rightly Moving to Reduce Barriers for Companies such as Uber and Lyft, HILL (Feb. 9, 2017), http://thehill.com/blogs/pundits-blog/technology/318635-newyork-is-rightly-moving-to-reduce-barriers-for-companies [https://perma.cc/HV4N-PBCL] (explaining that in New York state, "the cab industry has doubled down, using local insurance requirements and other regulatory clubs to continue to bludgeon Uber and Lyft").

${ }^{109}$ Cf. Carnes, supra note 108 ("These regulatory battles are a product of an entrenched monopoly's taking for granted that a more efficient, more responsive service might emerge."). ${ }^{110}$ See Adam Lashinsky, Uber Banking on World Domination, FoRTUNE (Sept. 18, 2014), http://fortune.com/2014/09/18/uber-banks-on-world-domination/ [https://perma.cc/3Y6GYV8G].

${ }^{111}$ See Downes, supra note 41 ('Indeed, according to Kalanick, the company has spent much of its young life fighting in courts, public utility commissions, and city councils for the ability to offer any service at all. Uber has already fought charges, fines, and bans in San Francisco, Chicago, Massachusetts, New York, Washington D.C, and recently in Toronto, where city officials have charged the company with dispatching rides without a license."). These responsive reactions by regulators are typical of what is happening throughout the country. See, e.g., Tim Elfrink, UberX will Launch in Miami Today, Defying Miami-Dade's Taxi Laws, MiAMI NEw TIMES (June 4, 2014), http://www.miaminewtimes.com/news/uberx-will-launchin-miami-today-defying-miami-dades-taxi-laws-6533024 [https://perma.cc/LGK7-RC7Z]. New Orleans regulators even sent Uber a cease-and-desist before it began operating in the city. See Jeanie Riess, Why New Orleans Doesn't Have Uber, GAMBIT (Feb. 4, 2014), https://www.bestofneworleans.com/gambit/why-new-orleans-doesnt-have-

uber/Content?oid=2307943 [https://perma.cc/FM4W-6ZRP].

${ }^{112}$ See note 97. 
companies had to be "warriors" and keep on fighting. ${ }^{113}$ Uber was also quite willing to state its disrespect for government officials in public. ${ }^{114}$ In 2012, at TechCrunch Disrupt, Travis Kalanick criticized lawmakers, alleging that they used three dubious strategies to challenge Uber: (1) they took steps to protect the industry they regulated; (2) they labelled something illegal if it didn't fit neatly within their pre-existing categories; and (3) they didn't do anything until they had the chance to assess the "optics" of the situation. ${ }^{115}$ In 2013, Kalanick said to a luncheon for Members of Congress that the anticompetitive measures aimed at Uber by local regulators were the result of regulatory capture by the taxi industry. ${ }^{116}$ By 2014 , Kalanick was blunt about the way he viewed regulators: "We're in a political campaign, and the candidate is Uber and the opponent is [] named Taxi. . . Nobody likes him, he's not a nice character, but he's so woven into the political machinery and fabric that a lot of people owe him favors." 117

113 Julie Bort, Uber CEO: Bring On The Cheap Competition, Bus. INSIDER (Sep. 12, 2012), http://www.businessinsider.com/uber-ceo-travis-kalanick-lyft-2012-9

[https://perma.cc/8RSC-JCFA] (quoting Travis Kalanick's interview at TechCrunch Disrupt SF 2012: "You have to be a fighter, kind of be a warrior. If not, you should go do something that's a little less disruptive.").

${ }^{114}$ See Lunden, supra note 60. By late 2010, Ryan Graves, CEO of Uber at the time of the initial cease-and-desist in California, had stepped down in favor of Travis Kalanick. See Julian Chokkattu \& Jordan Crook, A Brief History of Uber, TECHCRUNCH (Aug. 14, 2014), https://techcrunch.com/gallery/a-brief-history-of-uber/slide/14/ [https://perma.cc/BC8QFK2N]. Whether coincidental or not with that change in management and/or the fights with regulators in New York, by 2011, Uber had become publicly more hostile towards regulations and regulators than it was in 2010.

${ }^{115}$ See Lunden, supra note 60.

116 Kalanick told Congressman Goodlatte in a public question-and-answer session at a Congressional Internet Caucus Advisory Committee luncheon that Uber had to fight anticompetitive measures in many locales as the result of regulatory capture. Kalanick maintained that the only reason Uber was able to counter the regulators was through use of social media by appealing to its large consumer base. See Cong. Internet Caucus Advisory Comm., 2013 State of the Net Luncheon Keynote: Rep. Goodlatte w/ Travis Kalanick, CEO of Uber, YouTUBE (Jan. 22, 2013), https://www.youtube.com/watch?v=gFgjEGgS5-o.

${ }^{117}$ Liz Gannes, Travis Kalanick: Uber Is Raising More Money to Fight Lyft and the “Asshole” Taxi Industry, RECODE (May 28, 2014), https://www.recode.net/2014/5/28/116273 54/travis-kalanick-uber-is-raising-more-money-to-fight-lyft-and-the [https://perma.cc/RUV4RX4W]. 
Despite the public criticisms described above, Uber was quite willing to work behind the scenes to influence regulators. ${ }^{118}$ In addition, Uber learned the power of its large user base. ${ }^{119}$ Uber demonstrated in Washington, D.C. how easily it could mobilize the many consumers of its services to provide direct pressure on their representatives in state and local government. ${ }^{120}$ As a result of the many resources available to it, ${ }^{121}$ Uber has been able to adopt a strategy of being one thing for one audience (highly-paid lobbyists for politicians) and a different entity altogether for a second audience (a social movement against backward-thinking regulators for its users).

This willingness to fight would continue even when conditions changed. While Uber had been fighting to launch its black-car service in cities around the world, three companies in San Francisco had begun offering peerto-peer ridesharing in which noncommercial drivers use their privately-owned cars to offer rides on-demand. ${ }^{122}$ Despite its previous interactions with Uber

${ }^{118}$ See Sottek, supra note 102 ("local lobbying registration records indicate the company hired private lobbyists in at least 50 US cities and states and has hired at least 161 people to lobby for its interests").

${ }^{119}$ See Laogoria-Chafkin, supra note 74 (quoting Kalanick) ("What we did in Chicago, what we do in all these cities, is reach out to all of our users and say, take action-email your councilperson; email the mayor. . . . Uber riders are the most affluent, influential people in their cities. When we get to a critical mass, it becomes impossible to shut us down.").

${ }^{120}$ See Downes, supra note 41 (writing that "Uber and its kin have been saved not by spending equal amounts of money lobbying, litigating, and performing other unsavory acts, but by mobilizing a vocal army of loyal customers, who Tweet, Facebook, blog and show up at city council meetings to shout down the illogic of traditional regulators").

${ }^{121}$ In the summer of 2017 , Uber was valued at $\$ 68.5$ billion. Amie Tsang, Morning Agenda: Proving Uber's Real Value, N.Y. TIMES (Aug. 24, 2017), https://www.nytimes.com/2017/08/24/business/dealbook/uber-revenue-valuation-ceoimmelt.html? [https://nyti.ms/2vr6Ylx]. As of July 2017, Uber had received over \$11 billion in funding. See Uber Funding Rounds, CRUNCHBASE, https://www.crunchbase.com/organization/uber/funding_rounds/funding_rounds_list [https://perma.cc/B6C7-G3DA].

${ }^{122}$ See STONE, supra note 3, at 197-200. See also Ronnie Kerr, When Lyft Was Young: The Early Years, VATOR (May 3, 2016), http://vator.tv/news/2016-05-03-when-lyft-was-youngthe-early-years-of-lyft [https://perma.cc/B29K-28LP] (Lyft launched in San Francisco in August 2012); Tomio Geron, SideCar Acquires Austin's HeyRide, Launches in Los Angeles, Austin, Philadelphia, FoRBES (Feb. 13, 2014), https://www.forbes.com/sites/tomiogeron/2013 /02/14/sidecar-acquires-austins-heyride-launches-in-los-angeles-austin-

philadelphia/\#70332a528891 [https://perma.cc/3XSN-AT5C] (Sidecar in early 2013 celebrated its one year anniversary of launch in San Francisco); Jennifer Van Grove, Wingz Takes On Uber with Flat Fares for Airport Rides, SAN DIEGO TRIB. (Mar. 22, 2016), 
and its eventual accommodation of the black car service, the CPUC returned to the same punitive enforcement mechanism it always used: it issued ceaseand-desist letters to Lyft, Sideshow, and Tickengo. ${ }^{123}$ The companies, however, continued to operate. ${ }^{124}$ The CPUC responded by issuing citations for $\$ 20,000$ fees to Lyft and Sidecar. ${ }^{125}$ The companies protested publicly, arguing that the charter-carrier regulations that the CPUC cited were inapplicable to their business models. ${ }^{126}$ In this now-familiar refrain of (1) launch of innovative service; (2) cease-and-desist letters issued by regulators; (3) continued operation by innovators; (4) imposition of fees by regulators; and (5) public protest, there was one indication that something had changed: the CPUC indicated that it would work with the companies to determine rules to regulate their services. ${ }^{127}$

Uber's initial response to these developments in its hometown was to try to get the ridesharing companies shut down. ${ }^{128}$ Even though the CPUC

http://www.sandiegouniontribune.com/business/technology/sdut-wingz-san-diego-airportrides-2016mar22-story.html [https://perma.cc/PX29-EJHA] (San Francisco-based Wingz, originally known as Tickengo, launched in 2011).

${ }^{123}$ Tomio Geron, Ride-Sharing Startups Get California Cease-And-Desist Letters, ForBES (Oct. 8, 2012), https://www.forbes.com/sites/tomiogeron/2012/10/08/ride-sharing-startupsget-california-cease-and-desist-letters/\#282132a451d3 [https://perma.cc/5LGB-G2J8].

${ }^{124}$ See Ryan Lawlor, While The California PUC Cracks Down on Ride-Sharing, Sidecar and Lyft Commit to Staying on the Road, TECHCRUNCH (Oct. 8, 2012), https://techcrunch.com/2012/10/08/cpuc-ride-sharing-c-and-d/ [https://perma.cc/9EEDE76G].

${ }^{125}$ See Press Release, Cal. Pub. Utils. Comm'n, CPUC Cites Passenger Carriers Lyft, Sidecar, and Uber \$20,000 Each For Public Safety Violations (Nov. 13, 2012), http://www.cpuc.ca.gov/uploadedFiles/CPUC_Public_Website/Content/Safety/Transportation _Enforcement_and_Licensing/CPUCCitesPassengerCarriersLyftSideCarandUber20000Eachf orPublicSafetyViolations.pdf [https://perma.cc/24NE-DER2] (citations for $\$ 20,000$ issued to Lyft, Sidecar, and Uber for operating charter-party carriers without proper licenses).

${ }^{126}$ See Lawlor, supra note 124 (indicating each company's reasons why citations are not applicable to them); see also Logan Green \& John Zimmer, Defending Lyft, LYFT BLOG (Nov. 14, 2012), https://blog.lyft.com/posts/2012/11/14/defending-lyft [https://perma.cc/XEA8NKKP] ("We oppose this citation as Lyft is not a charter-party carrier, we are a peer-to-peer ridesharing platform. This is a case of regulators trying to put us into a box that doesn't fit.").

${ }^{127}$ Green \& Zimmer, supra note 134 ("The CPUC understands the importance of ridesharing and they are discussing opening up a rulemaking process to design new regulations that support peer-to-peer transportation.”).

${ }^{128}$ Uber at this time was not a ridesharing company; it was operating only using drivers already holding a commercial license in the cities they drove in. See STONE, supra note 3, at 196. Kalanick stated on a podcast in 2011-when rumors about ridesharing services were 
indicated that it was interested in speaking with the ridesharing companies to receive their help to write new rules, ${ }^{129}$ Uber ignored the opportunity to collaborate and launched a lobbying campaign with the CPUC against Lyft and SideCar. ${ }^{130}$ Meanwhile, it was likely working on a competitive product in case regulators allowed ridesharing companies to operate in California. ${ }^{131}$

In January 2013, the CPUC issued a consent decree with temporary rules that protected consumers until a more complete analysis of the industry could be undertaken. ${ }^{132}$ Uber signed the decree as well and began offering ridesharing services. ${ }^{133}$ California eventually became the first state to write permanent regulations aimed specifically at ridesharing companies. ${ }^{134}$ These

already beginning to circulate in startup circles - that "it would be illegal" to offer that service. Kalanick stated that, when Uber begins operating in a city, it tries to be "totally legitimately legal." See id. at 199.

${ }^{129}$ The CPUC allowed Lyft and SideCar to continue operating and invited the companies to talk about how to move forward. See STONE, supra note 3, at 200. The lawyers for Lyft were not confrontational, but instead adopted an attitude of collaboration and persuasion. Id at 202-04. Looking back at the experience, the main lawyer for Lyft speculated that if Uber, with its more confrontational attitude, had been the main proponent of ridesharing, the TNC regulations would have included more stringent requirements. Id. at 204.

${ }^{130}$ Kalanick argued directly to CPUC commissioners that ridesharing companies should be banned in California. STONE, supra note 3, at 203.

${ }^{131}$ This is a logical assumption based on the timing of events. The Consent Decree with the CPUC was signed at the end of January 2013. See Term Sheet for Settlement between the Safety and Enforcement Division of the California Public Utilities Commission and Uber Technologies, Inc., http://www.cpuc.ca.gov/uploadedFiles/CPUC_Public_Website/Content/S afety/Transportation_Enforcement_and_Licensing/Enforcement_Actions_Transportation_Net work_Companies/UberTermSheetforSettlement.pdf [https://perma.cc/5GVK-FHFV]. On April 12 2013, Uber rolled out "UBERX Rideshare." See Gerry Shih, UberX Rideshare Expanding: Controversial App Offering Taxi-Like Services Has New Plan For Big Cities, HuFFPoST (Apr. 12, 2013, 11:54 PM), http://www.huffingtonpost.com/2013/04/13/uber-toexpand-private-ri_n_3074061.html [https://perma.cc/G2XU-BFWP] ("Speaking to reporters in a conference call ... Kalanick said he had withheld from launching a private vehicledispatching business until now due to its 'extreme regulatory risk."').

132 STONE, supra note 3, at 204.

133 Press Release, Cal. Pub. Utils. Comm'n, CPUC Enters into Operating Agreement With Uber, (Jan. 31, 2013), http://docs.cpuc.ca.gov/PublishedDocs/Published/G000/M047/K151/47 151370.PDF [https://perma.cc/TA85-QX29] ("[The CPUC] will suspend its cease and desist notice to Uber, as well as the $\$ 20,000$ citation issued on Nov. 13, 2012, pending outcome of the CPUC's rulemaking.").

${ }^{134}$ Heather Somerville, California Becomes First State to Regulate Ride-Sharing Services, SAN JOSE MERCURY NEwS (Sept. 20, 2013), http://www.mercurynews.com/2013/09/20/califo rnia-becomes-first-state-to-regulate-ride-sharing-services/ [https://perma.cc/PTZ8-ATJQ]. 
regulations became a template used by many other jurisdictions to craft their own regulations for ridesharing companies. ${ }^{135}$

\section{Uber Broadens its Defiance}

Shortly after announcing its own ridesharing services, Uber publicly released its principled approach to the conflicts between ride sharing and regulation in the form of a white paper: Principled Innovation: Addressing the Regulatory Ambiguity Around Ridesharing Apps. ${ }^{136}$ Despite its claim in the White Paper to only operate where it has at least tacit regulatory approval, ${ }^{137}$ Uber used its resources-financial and technological-to work around regulatory restrictions.

In some cities-like Austin, Texas-Uber used a different strategy to defy regulators: it had sufficient resources to ignore the potential revenues from the city and so opted to leave when the city continued to require background checks for all drivers. ${ }^{138}$ In Portland, Oregon, Uber adopted yet another strategy, demonstrating not only its ongoing disrespect for regulation, but also the resources - this time not financial, but technical - it had at its disposal. The company's engineers developed a new technology named Greyball that recognized when an enforcement officer used Uber's app to hail

\footnotetext{
${ }^{135}$ For example, Seattle, Texas, and Massachusetts created rules for Transportation Network Companies. See Mass. Pub. Utils. Transp. Dep't, Final Transportation Network Companies Regulations Published, MASS.GOV (Sep. 22, 2017), https://www.mass.gov/news/finaltransportation-network-companies-regulations-published [perma.cc/7BXV-ZW8Y]; Tex. Dep't of Licensing and Transp., Transportation Network Companies, TDLR, https://www.tdlr.texas.gov/tnc/tnclaw.htm [https://perma.cc/NSK9-8JED]; SEATTLE, WASH., MUN. CODE ch. 6.310 (2014), https://library.municode.com/wa/seattle/codes/municipal_code? nodeId=TIT6BURE_SUBTITLE_IVNELICO_CH6.310TAFREVE [https://perma.cc/FVC2LGVE].

136 Travis Kalanick, Uber White Paper 1.0, BENEDELMAN.ORG (Apr. 12, 2013), http://www.benedelman.org/uber/uber-policy-whitepaper-printfriendly.pdf [https://perma.cc/49YU-6UVK].

${ }^{137} \mathrm{Id}$.

138 When residents of Austin, Texas did not approve favorable rules for the regulation of ridesharing companies, Uber pulled out of Austin completely. See Eliana Dockterman, Uber and Lyft Are Leaving Austin after Losing Background Check Vote, FORTUNE (May 8, 2016), http://fortune.com/2016/05/08/uber-lyft-leaving-austin/ [https://perma.cc/88ZX-78KU].
} 
a car. ${ }^{139}$ Once such an officer is identified as requesting a ride, the Greyball software immediately cancels the ride. The result was that agents had a difficult time collecting evidence that the company was operating illegally. Allegedly, Uber used Greyball around the world to defy regulatory bans. ${ }^{140}$ The U.S. Department of Justice has launched an investigation into the company's use of Greyball to determine if it constituted obstruction of justice. $^{141}$

There are other instances of Uber leveraging its technological acumen to skirt what is legally acceptable. For instance, in another program (codenamed Hell) the company developed software that could track its drivers to identify those Uber drivers who also drove for other ride-sharing competitors, specifically Lyft. ${ }^{142}$ The software then targeted those drivers and prioritized placing customers in their cars to keep them from switching to a different app. ${ }^{143}$ Once Uber's Hell program was revealed, drivers filed a class action lawsuit against the company for violating driver privacy and sought damages for anti-competitive behavior. ${ }^{144}$

Additional deceptive practices have also been alleged. A lawsuit has been filed against the company alleging breach of contract, unjust enrichment, fraud, and unfair competition on the grounds that Uber uses software that shows riders fares based on one route but directs drivers to take a shorter, more efficient route. ${ }^{145}$ Riders are charged for the longer route while drivers

139 Mike Isaac, How Uber Deceives the Authorities Worldwide, (March 3, 2017), https://www.nytimes.com/2017/03/03/technology/uber-greyball-program-evade-

authorities.html [https://nyti.ms/2lngDck].

${ }^{140} I d$.

${ }^{141}$ Mike Isaac, Justice Department Expands Its Inquiry into Uber's Greyball Tool, N.Y. TiMES (May 5, 2017), https://www.nytimes.com/2017/05/05/technology/uber-greyballinvestigation-expands.html [https://nyti.ms/2peOnpF].

${ }^{142}$ See Carolyn Said, Feds Probe Uber 'Hell' Program for Tracking Lyft Drivers, S.F. GATE (Sept. 8, 2017) http://www.sfgate.com/business/article/Feds-probe-Uber-Hell-program-fortracking-12183963.php [https://perma.cc/S7YA-LRWE].

${ }^{143}$ Remember, Uber also challenged a subpoena from the City of San Francisco over concerns of a driver's right to privacy. See id.

${ }^{144}$ Megan Rose Dickey, Uber Gets Sued over Alleged 'Hell' Program to Track Lyft Drivers, TECHCRUNCH (Apr. 24, 2017), https://techcrunch.com/2017/04/24/uber-hell-lawsuit/ [https://perma.cc/KT6J-Q5FF].

${ }_{145}$ See David Kravets, Uber Said to Use 'Sophisticated Software' to Defraud Drivers, Passengers, ARS TECHNICA (Apr. 6, 2017, 1:54 PM), https://arstechnica.com/techpolicy/2017/04/uber-said-to-use-sophisticated-software-to-defraud-drivers-passengers/ [http://perma.cc/BVG7-LU79]. 
are paid for the shorter route, with Uber pocketing the difference. ${ }^{146}$ More recently, Uber has been accused of renting cars it knew were defective to its drivers in Singapore. ${ }^{147}$

Despite all the regulatory disputes and lawsuits, Uber continued to act as if regulations did not apply to them. In late 2016, Uber, still headquartered in San Francisco, announced that, although its initial testing of its driverless cars had taken place in Pittsburgh, where it will continue to run, it was now bringing them to San Francisco, and they would be publicly available. ${ }^{148}$ The California Department of Motor Vehicles issued rules for testing autonomous vehicles in May of 2014 and required all manufacturers of driverless cars to register them and receive a permit before testing them on California streets. ${ }^{149}$ Twenty companies complied with these regulations, including Waymo, Tesla, and General Motor's Cruise subsidiary. ${ }^{150}$ Uber, however, adopted a familiar stance by beginning to test-drive its autonomous vehicles in San Francisco without first registering with the DMV. ${ }^{151}$ The DMV immediately stated that Uber was operating illegally for failure to register the cars on its site and issued a cease-and-desist order. $^{152}$ The DMV subsequently pulled the

${ }^{146} \mathrm{Id}$

${ }^{147}$ Douglas MacMillan \& Newley Purnell, Smoke, Then Fire: Uber Knowingly Leased Unsafe Cars to Drivers, WALL ST. J. (Aug. 3, 2017), https://www.wsj.com/articles/smoke-then-fireuber-knowingly-leased-unsafe-cars-to-drivers-1501786430?mg=prod/accounts-wsj.

${ }^{148}$ Darrell Hetherington, Uber's Self-Driving Cars Start Picking Up Passengers in San Francisco, TECHCRUNCH (Dec. 14, 2016), https://techcrunch.com/2016/12/14/ubers-selfdriving-cars-start-picking-up-passengers-in-san-francisco/ [https://perma.cc/2UZG-WDED].

149 See California Dep't of Motor Vehicles, Testing of Autonomous Vehicles, CA.gOv, https://www.dmv.ca.gov/portal/dmv/detail/vr/autonomous+/testing [https://perma.cc/C6U57BDT].

${ }^{150}$ See Matt McFarland, Uber Blows Off Regulators, Tests Self-Driving Volvos in California, CNN (Dec. 14, 2016, 9:38 AM), http://money.cnn.com/2016/12/14/technology/uber-selfdriving-cars-california-dmv/index.html [https://perma.cc/DM3L-VGJV].

${ }^{151}$ Uber claimed that the DMV rules did not apply to their self-driving cars. See Christopher Mele, In a Retreat, Uber Ends Its Self-Driving Car Experiment in San Francisco, N.Y. TIMES (Dec. 21, 2016), https://www.nytimes.com/2016/12/21/technology/san-francisco-californiauber-driverless-car-.html [https://nyti.ms/2jRDb0f] (stating that Uber officials contend, under the letter of California law, that the company did not need a permit because the Motor Vehicles Department defined autonomous vehicles as those that drive "without the active physical control or monitoring of a natural person" and Uber's drivers interact with the car more substantially).

${ }^{152}$ Alison Griswold, Letter: California's DMV Says Uber "Must Cease” Operating Its SelfDriving Cars, QUARTZ (Dec. 14, 2016), https://qz.com/863718/uber-received-a-stern-letterfrom-the-california-dmv-telling-it-to-cease-operating-its-self-driving-cars/ 
registration on all of Uber's self-driving cars (which were registered as traditional vehicles) and demanded that the company go through the necessary steps to receive a permit. ${ }^{153}$ Rather than comply, Uber echoed its reaction in Austin and moved its autonomous vehicle operations to Phoenix. ${ }^{154}$ Within three months, however, Uber returned to San Francisco. ${ }^{155}$ With very little fanfare, it complied with the DMV's licensing regime and began once again to test its vehicles on the city's streets. ${ }^{156}$

The attitude of disruption of anything and everything in its path began to catch up to Uber and Travis Kalanick in 2017. In the first three-quarters of the year, Uber has dealt with six major lawsuits involving sexual harassment, privacy violations, driver classification, intellectual property, deceptive practices and fights between Board members. ${ }^{157}$ Travis Kalanick resigned as $\mathrm{CEO}^{158}$ and the Board voted to remove his super-voting rights, although he will retain a seat on the Board. ${ }^{159}$

[https://perma.cc/2D78-GXC4]; see Mike Isaac, Uber Expands Self-Driving Car Service to San Francisco. D.M.V. Says It's Illegal., N.Y. TimeS (Dec. 14, 2016), https://www.nytimes.com/2016/12/14/technology/uber-self-driving-car-san-francisco.html [https://nyti.ms/2kgIzd1].

${ }^{153}$ Avie Schneider, Uber Stops Self-Driving Test in California After DMV Pulls Registrations, NPR (Dec. 21, 2016), http://www.npr.org/sections/thetwo-way/2016/12/21/506525679/uberstops-self-driving-test-in-california-after-dmv-pulls-registrations [https://perma.cc/WK3E9AHW].

${ }^{154}$ Greg Bensinger, Uber Moves Self-Driving Car Test to Arizona After Regulatory Defeat in California, WALL ST. J. (Dec. 22, 2016), https://www.wsj.com/articles/uber-moves-selfdriving-car-test-to-arizona-after-regulatory-defeat-in-california-1482442732.

${ }^{155}$ Greg Bensinger, Uber's Self-Driving Cars Returning to California Roads, WaLl ST. J. (Mar. 7, 2017), https://www.wsj.com/articles/ubers-self-driving-cars-returning-to-californiaroads-1489011778.

${ }^{156}$ See Adam Brinklow, Uber Self-Driving Cars Coming Back to San Francisco, CuRBED S.F. (Mar. 9, 2017, 9:59 AM), https://sf.curbed.com/2017/3/9/14869564/uber-self-driving-returnsf [https://perma.cc/2WEK-5WZ4].

${ }^{157}$ Anita Balakrishnan, Six Looming Legal Threats That Could Still Sink Uber, CNBC (June 18, 2017, 3:42 PM), https://www.cnbc.com/2017/06/18/uber-faces-big-legal-threats-lawyers.html [https://perma.cc/P2HN-ANRF].

${ }^{158}$ Mike Isaac, Inside Travis Kalanick's Resignation as Uber's C.E.O., N.Y. TIMES (June 21, 2017), https://www.nytimes.com/2017/06/21/technology/uber-travis-kalanick-finalhours.html [https://nyti.ms/2sSsX7c].

${ }^{159}$ Katie Benner \& Mike Isaac, Uber's Board Approves Changes to Reshape Company's Power Balance, N.Y. TIMES (Oct. 3, 2017), https://www.nytimes.com/2017/10/03/technology/ubers-board-approves-changes-to-reshapepower-balance.html [https://nyti.ms/2xR33kL]. 
Over the course of its short life, Uber became the poster child of disruption. The company is known for not only disrupting the taxi industry, but also for disrupting regulatory systems. ${ }^{160}$ The conciliatory language of the 2010 blog post, describing a desire to work with regulators, was lost in the need to fight outright bans, punitive fees, and expensive lawsuits. As Uber pushed into new cities and continued its regulatory battles, investors and the public initially responded with support and encouragement. ${ }^{161}$ Unfortunately, Uber applied that same aggressive defiance to every aspect of its business, and negative consequences continue to arise. ${ }^{162}$ It is unlikely that one single factor caused Uber's corrosive culture. Nevertheless, it is interesting to ponder whether Uber might have adopted a company mantra other than defiance, if regulators had reached out with more collaborative tools at the time the company was still looking to educate and work with rulemakers. ${ }^{163}$

\section{B. Airbnb}

Like Uber, Airbnb helped shape the platform economy in San Francisco. Unlike Uber, it had no immediate confrontations with California regulators. In fact, Airbnb operated for six years, ${ }^{164}$ simply ignoring

\footnotetext{
${ }^{160}$ See, e.g., Helderman, supra note 76 ("Uber has pioneered not just a new sort of taxi service but also a new way to change long-standing local ordinances.").

${ }^{161}$ See, e.g., Brown, supra note 4 (explaining why investors and users support Uber). See ADAM LASHINSKY, WILD RIDE: INSIDE UBER'S QUEST FOR WORLD DOMINATION 98 (2017) (describing Uber's launch into new markets and the public media's response).

${ }^{162}$ See, e.g., Bruce Sterling, Actual Sharista Guys Never Liked Uber Very Much, WIRED (Aug. 3 , 2017), https://www.wired.com/beyond-the-beyond/2017/07/actual-sharista-guys-neverlike-uber-much/ [https://perma.cc/J4AN-HBMZ] (describing the long-lasting, toxic impact of Uber's example). New consequences of Uber's deceptive practices continue. See, e.g., Greg Nibler, Uber Will Be Banned from Operating in London for Deceptive Practices, DIGITAL TRENDS (Sept. 22, 2017), https://www.digitaltrends.com/dt-daily/dt-daily-uber-bannedlondon/ [https://perma.cc/6UHY-VCAZ].

${ }^{163} C f$. Sterling, supra note 162 (Uber's “' don't ask permission, ask for forgiveness later' strategy is now part of the Silicon Valley startup playbook. Thousands of entrepreneurs now likely believe that breaking the law is fine for the sake of disruption.").

${ }^{164}$ Cf. STONE, supra note 3, at 17 (showing that the first guest to airbedandbreakfast.com arrived on October 16, 2007); Leena Rao, Y Combinator's Airbed and Breakfast Casts a Wider Net for Housing Rentals as AirBnB, TeCHCRUNCH (May 4, 2009), https://techcrunch.com/2009/03/04/y-combinators-airbed-and-breakfast-casts-a-wider-net-forhousing-rentals-as-airbnb/ [https://perma.cc/C6XH-6EBD] (showing that Airbed and Breakfast eventually relaunched as Airbnb); Carolyn Said, Airbnb's Long, Complex History
} 
California's 1981 law that banned all short-term rentals. ${ }^{165}$ When the Board of Supervisors, San Francisco's legislative body, finally addressed the need to regulate home-sharing platforms like Airbnb, the Board had already recognized Airbnb's benefit. ${ }^{166}$ The new law limited the number of days a property could be "shared," and it required all hosts to register with the city, but the city had a hard time enforcing these requirements. ${ }^{16}$

Although the General Counsel of Airbnb has asserted that the company had a desire to be authentic and transparent with customers and government officials, ${ }^{168}$ a series of harsh actions from state legislators

\begin{tabular}{lllllll}
\hline with San Francisco, & S.F. GATE (May 1, 2017, & 5:08 & PM)
\end{tabular}

http://www.sfgate.com/business/article/Airbnb-s-long-complex-history-with-San-

11113222.php [https://perma.cc/FR3D-7TW7] (stating that prior to October 2014, short-term rentals - i.e. rentals of less than thirty days - were illegal).

${ }^{165}$ Mary Catherine Wiederhold, Illegal Short-Term Rentals, MCW REAL EsTATE L. (Mar. 18, 2012), http://mcwrealestatelaw.com/tenant-rights/illegal-short-term-rentals/ [https://perma.cc/ QBW7-G8GH] (stating that in 1981, the San Francisco Board of Supervisors passed an ordinance that forbade a landlord from renting an apartment for less than 30 days without obtaining a permit to convert the property to tourist use).

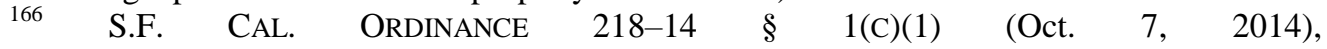
http://www.sfbos.org/ftp/uploadedfiles/bdsupvrs/ordinances14/o0218-14.pdf

[https://perma.cc/DQ2U-HCTK] (providing that "the advent of new technology, the rise of the sharing economy, and the economic and social benefit to residents of sharing resources" led to the continued increase in short-term rental activity and prompted the city to change its laws to "create a pathway to legalize this activity"); see Marcus Wohlsen, San Francisco's New Housing Rules Are the Best Thing to Happen to Airbnb, WIRED (Oct. 8, 2014), https://www.wired.com/2014/10/san-franciscos-new-limits-best-thing-happen-airbnb [https://perma.cc/E2W7-7PTQ].

167 See Megan Barber, Airbnb vs. the City, CuRBed (Nov. 10, 2016), https://www.curbed.com/2016/11/10/13582982/airbnb-laws-us-cities [https://perma.cc/FTN6GMKF] (Describing that San Francisco is imposing a new law, because San Francisco regulators had such a hard time enforcing 2014 Airbnb law and that the new law puts the burden of enforcement on Airbnb itself.); see also Carolyn Said, S.F. to Create City Office to Enforce Airbnb Law, S.F. GATE (July 2, 2015), http://www.sfgate.com/business/article/S-Fto-create-city-office-to-enforce-Airbnb-law-6361832.php [https://perma.cc/98TV-792Z] (stating that by July 2015, only 700 hosts, of the more than 5000 listing properties on Airbnb's platform had registered with the city pursuant to the 2014 law's requirements).

${ }^{168} C f$. STONE, supra note 3, at 213, 215 (explaining that Airbnb's executives spent months hashing out the core values of the company and noting that that Belinda Johnson, the General Counsel, told New York regulators that the company "wanted to build a positive kind of credibility with cities" that was authentic to the founders). 
changed its approach. ${ }^{169}$ New York state regulators did not see Airbnb in the same light in which it saw itself. ${ }^{170}$ In part, this unfriendly response was due to Mayor Michael Bloomberg's long-time plan to go after avaricious landlords, but complaints about one of Airbnb's New York hosts helped to produce the 2010 law that contained a statewide prohibition of short-term rentals. ${ }^{171}$ The law made it illegal to rent out a residence for less than 30 days unless the permanent resident was also present. ${ }^{172}$

At this time, Airbnb was still attempting to cooperate with government officials and offered to work with New York to pass a law that would impose an occupancy tax on its New York hosts. ${ }^{173}$ Nevertheless, the state's harsh punitive reactions continued when the New York Attorney General issued a subpoena for the names, addresses, and contact information for all hosts in the state. ${ }^{174}$

In response, Airbnb dropped its cooperative attitude. ${ }^{175}$ About to close a Series C funding round for $\$ 200$ million, ${ }^{176}$ Airbnb used its resources to take

169 Alison Griswold, Move Over Uber: Airbnb Is No Longer the Nice Guy of the Sharing Economy, QUARTZ (Dec. 5, 2016), https://qz.com/842996/what-happens-when-a-30-billionstartup-stops-being-nice-and-starts-being-real/ [https://perma.cc/3B9V-3DKX] ("After years of playing the nice guy, Airbnb now finds itself on the defensive in some of its biggest markets, and the pressure doesn't suit. The company has unleashed lawsuits, held rallies, and spent millions on lobbying campaigns.").

${ }^{170}$ See STONE, supra note 3, at 215 (quoting New York State Senator Liz Kreuger saying "I have never dealt with a company as disingenuous as Airbnb has been over and over again.").

${ }^{171} I d$. at 216-21 (describing in detail the Hotel Toshi debacle that helped to produce "a stifling law in New York City").

${ }^{172}$ Dailey, supra note 84.

173 Brian Chesky, Who We Are, What We Stand for, AirbnB: Blog (Oct. 3, 2013), http://blog.atairbnb.com/who-we-are/ [https://perma.cc/9QDZ-76GH] ("On behalf of our New York City community, we want to work for sensible laws that allow New Yorkers to share their space, earn extra income, and pursue their American Dream."). Airbnb also offered to set up a 24/7 hotline for complaints by New York residents about Airbnb rentals. STONE, supra note 3, at 228. New York policymakers were not impressed. See id. at 228-29.

${ }^{174}$ Matt Chaban, Attorney General Eric Schneiderman Hits Airbnb with Subpoena for User Data, N.Y. DAILY News, (Oct. 7, 2013), http://www.nydailynews.com/news/national/stateairbnb-article-1.1477934 [https://perma.cc/3RQ3-HPYY]. According to Brad Stone, the Attorney General's office believed that, despite its public announcements to the contrary, Airbnb was not attempting to take illegal hoteliers off its site or actually working on a way to collect occupancy taxes. STONE, supra note 3, at 228.

${ }^{175}$ Cf. Gerry Shih, Accommodation Renter Airbnb Fights NY State Subpoena on Sublets, REUTERS (Oct. 9, 2013, 6:23 PM), http://www.reuters.com/article/us-airbnbsubpoena/accommodation-renter-airbnb-fights-ny-state-subpoena-on-sublets- 
New York to court. ${ }^{177}$ Airbnb's lawyers argued that the subpoena was too broad and violated its user's privacy. ${ }^{178}$ The judge in the case ruled in Airbnb's favor. ${ }^{179}$ The New York Attorney General issued a new subpoena that met the judge's concerns and eventually, with no other choice, Airbnb agreed to turn over anonymized data. ${ }^{180}$ Despite receiving the data it requested, the state of New York continued to refuse to come to an agreement with the company to legitimize short-term rentals. ${ }^{181}$ As a result of these prohibitions and demands in New York and other jurisdictions, ${ }^{182}$ Airbnb

idUSBRE9981AR20131009 [https://perma.cc/X73J-26KY] (noting that David Hantman, Airbnb's Head of Global Policy, criticized a subpoena for the records of all Airbnb hosts in New York State as "unreasonably broad" and vowed to fight it with "everything we've got"). ${ }^{176}$ See Airbnb Funding Rounds, CRUNCHBASE, https://www.crunchbase.com/organization/air bnb/funding_rounds/funding_rounds_list [https://perma.cc/E6SA-76GW] (showing that on October 28, 2013, Airbnb closed a Series C round with Founders Fund).

${ }^{177}$ Shih, supra note 175 ("Airbnb, the room-rental service, went to court Wednesday [October 9, 2013] to block a subpoena from the New York Attorney General").

${ }^{178} I d$. ("The subpoena would be difficult for the company to comply with because it covers data from hundreds of thousands of separate records, the company told the New York State Supreme Court in a filing."'); David Streitfeld, New York's Case Against Airbnb is Argued in Albany, N.Y. TIMES (Apr. 22, 2014), https://www.nytimes.com/2014/04/23/technology/alban y-judge-hears-case-against-airbnb.html [https://nyti.ms/2jczZk8] (quoting Airbnb's lawyer as criticizing the subpoena for its "extreme and incredible scope" and for asking for its user's "confidential information").

179 Nick Wingfield, A Victory for Airbnb in New York, N.Y. Times (May 13, 2014), https://www.nytimes.com/2014/05/14/technology/judge-quashes-new-york-subpoena-forairbnb-records.html [https://nyti.ms/2p7oF9Z].

${ }^{180}$ STONE, supra note 3, at 235. In 2015, Airbnb released additional data in response to continued complaint over a lack of transparency. See Yoav Gonen \& Amber Sutherland, Most Airbnb Rentals Violate the State's Short-Term Leasing Law, N.Y. Post (Dec. 2, 2015), http://nypost.com/2015/12/02/most-airbnb-rentals-violate-the-states-short-term-leasing-law/ [https://perma.cc/3H6F-BPYQ].

${ }^{181}$ STONE, supra note 3, at 276-77 (hotels and hotel workers' unions began to realize how much of a threat Airbnb was to their industry and lobbied politicians to not sign an agreement with the company).

${ }^{182}$ Cf. Griswold, supra note 169 (noting that, at the time the article was written, “Airbnb's peer-to-peer rentals [were] being scrutinized in Los Angeles; Miami Beach, Florida; Portland, Oregon; Toronto; Barcelona; and Berlin"); Niki Cervantes, Santa Monica Gets Even Tougher on Short-Term Vacation Rental 'Hosts', SANTA MoniCA LoOKOUT (Jan. 12, 2017), http://www.surfsantamonica.com/ssm_site/the_lookout/news/News-2017/January-

2017/01_12_2017_Santa_Monica_Gets_Even_Tougher_on_Short_Term_Vacation_Rental_H osts.html [https://perma.cc/2JCJ-WRXB] (describing registration restrictions that were imposed on Airbnb in the city of Santa Monica). 
quickly learned how to go to war with regulators and other government officials hostile to its business model. ${ }^{183}$

This new attitude towards outside threats to its business was also put to the test in Airbnb's hometown. In San Francisco, a coalition of housing activists, landlords, neighborhood groups, and hotel workers' unions were unhappy about the leniency and unenforceability of the 2014 short-term rental law in the city. ${ }^{184}$ They joined together to get sufficient signatures to place a proposition on the November 15, 2015 ballot. ${ }^{185}$ Proposition F, if approved by the city's voters, would severely limit the number of days permitted for shortterm rentals, require hosts and platforms to supply data on usage every quarter, and give standing to neighbors and activists to sue for violations of the rules. ${ }^{186}$

Having learned in New York and elsewhere that appeasement did not always work, Airbnb went to war. In June, Airbnb raised another round of funding, this time for $\$ 1.5$ billion, ${ }^{187}$ and quickly invested $\$ 8$ million to defeat

${ }^{183}$ Cf. Adrienne Jeffries, Airbnb Will Fight Regulators on Behalf of Host Who Was Fined \$2400, VERGE (June 5, 2013), https://www.theverge.com/2013/6/5/4398534/airbnb-newyork-fine-nigel-warren-public-policy-fight [https://perma.cc/53JT-TB3V] (noting that Airbnb was starting to "clash with regulators in New York City" and, for the first time, "proactively got[] involved in an individual case"). Stone has compared Brian Chesky, the CEO and founder of Airbnb, to Kalanick, stating that, although Chesky's reputation survived better in these early years than Kalanick's, Chesky was every bit as disruptive, determined, and unethical as Uber's CEO. See STONE, supra note 3, at 278.

${ }^{184}$ Carolyn Said, Prop. F Splits Neighbors on Whether Airbnb Hurts or Helps Housing, S.F. CHRONICLE (Oct. 17, 2015), http://www.sfchronicle.com/business/article/Prop-F-splitsneighbors-on-whether-Airbnb-hurts-6575919.php [https://perma.cc/4HTL-2KS2] ("Prop. F unites unlikely bedfellows - housing activists and landlords; unions, especially hotel workers; and neighborhood groups - to oppose short-term rentals.").

${ }^{185}$ Carolyn Said, Airbnb Foes Mount Campaign for S.F. Ballot Measure, S.F. GATE (May 1, 2015), http://www.sfgate.com/business/article/Airbnb-foes-mount-campaign-for-SF-ballotmeasure-6231816.php [https://perma.cc/2VBP-J58Z].

186 Tracey Lien, Everything You Need to Know About San Francisco's Airbnb Ballot Measure, L.A. TIMES (Oct. 30, 2015), http://www.latimes.com/business/technology/la-fi-tnairbnb-prop-f-san-francisco-20151029-htmlstory.html [https://perma.cc/KHR7-LLXL]; Said, supra note 68 (Prop. F supporters believed the city's existing regulations for short-term rentals were "toothless").

${ }^{187}$ Airbnb Funding Rounds, supra note 176 (noting that on June 28, 2015, Airbnb raised a Series E round for $\$ 1.5$ billion). 
the measure. ${ }^{188}$ It also demonstrated the power of its user base, mobilizing those who used its platform, whether as host or guest, to go door-to-door to convince voters that Prop. F was not the right way forward. On November 3, 2015, Prop. F was defeated. ${ }^{189}$

The city of San Francisco, however, had realized from this battle that a significant number of constituents were not satisfied with its apparent leniency with Airbnb and other home-sharing platforms. And, despite its victory, Airbnb's image in the Bay Area had been tarnished by some of its ads during the campaign. ${ }^{190}$ The Board of Supervisors soon began to debate how to pass and enforce a new, more restrictive regime for short-term rentals. In June of 2016, the new bill was passed, continuing to require all hosts to register with the city, but switching the burden of enforcement to Airbnb. ${ }^{191}$ If hosts listing properties in San Francisco had not registered with the city, Airbnb was subject to large fines (up to $\$ 1,000$ per day) and criminal penalties. ${ }^{192}$

Just as in New York, the company did not want to turn over data about its hosts or assume corporate liabilities for their actions. ${ }^{193}$ Shortly after the

${ }^{188}$ Biz Carson, Airbnb Has Spent More Than $\$ 8$ Million Fighting a Proposed Law in San Francisco, BUS. INSIDER (Sept. 28, 2015, 4:02 PM), http://www.businessinsider.com/airbnbspends-8-million-against-prop-f-2015-9 [https://perma.cc/9GF4-AJTJ].

${ }^{189}$ Kia Kokalitcheva, San Francisco Voters Reject 'Anti-Airbnb' Ballot Measure, ForTunE (Nov. 4, 2015), http://fortune.com/2015/11/04/san-francisco-votes-airbnb/ [https://perma.cc/46S2-R2XH] (quoting an Airbnb statement after the vote: "This victory was made possible by the 138,000 members of the Airbnb community who had conversations with over 105,000 voters and knocked on 285,000 doors. The effort showed that home sharing is both a community and a movement."). In contrast to the almost $\$ 8.5$ million Airbnb spent, supporters of Prop. F raised just \$1,138,567. City of San Francisco Initiative to Restrict ShortTerm Rentals, Proposition F (November 2015), BALlOTPEDIA, https://ballotpedia.org/City_of_San_Francisco_Initiative_to_Restrict_Short-

Term_Rentals,_Proposition_F_(November_2015) [https://perma.cc/HV6S-DF87] (listing funds raised by both sides).

190 See StONE, supra note 3, at 286-87. After the San Francisco vote, residents in other localities began to fight for restrictions on short-term rentals in their cities. Id. at 291.

${ }^{191}$ Cf. Joshua Sabatini, SF Legislators Approve Tougher Rules for Airbnb, S.F. EXAMINER (June 7, 2016, 3:25 PM), http://www.sfexaminer.com/sf-legislators-approve-tougher-rulesairbnb/ [https://perma.cc/UU8K-J9W7] (noting that the legislation imposed fines on the shortterm rental websites themselves for posting listings of unregistered residents).

${ }^{192}$ Id. For the latest version of the code, see S.F. ADMIN. CODE ch. 41, § 41A.5(g) (2017).

${ }^{193}$ Cf. Kia Kokalitcheva, Airbnb Sues Its Hometown over Latest Short-Term Rental Crackdown, FORTUNE (June 27, 2016), http://fortune.com/2016/06/27/airbnb-san-franciscolawsuit/ [https://perma.cc/38PS-68SG] (describing Airbnb's law suit against San Francisco 
law's passage, Airbnb filed a suit seeking an injunction to prevent the city from enforcing the law, arguing that the new ordinance violated the company's rights under the Communications Decency Act (CDA) and the First Amendment. ${ }^{194}$ In response to Airbnb's complaint, the Board of Supervisors passed Ordinance 178-16 which amended the law to "abandon[] any requirements or restrictions on the publication of a rental listing" and "ma[de] it a misdemeanor to collect a fee for providing booking services for the rental of an unregistered unit." 195 Nevertheless, Airbnb maintained its argument that the regulations violated their rights and added the argument that the regulations unlawfully imposed criminal strict liability. ${ }^{196}$ Airbnb used provisions of the CDA to argue that the company was not responsible - and could not be held accountable- for what properties people decided to list on its platform. ${ }^{197}$

As Airbnb was waiting for the ruling in the San Francisco, Governor Cuomo of New York signed a new law imposing harsh fines on short-term rental hosts that violate its provisions. ${ }^{198}$ New York had already banned rentals of fewer than 30 days in a multi-unit building, but the new law made listing an advertisement for such a prohibited rental also illegal, perhaps

challenging the regulations that required it to share data on rentals and imposed stiff fines for every unlisted property that appeared on its website).

${ }^{194}$ Complaint for Declaratory and Injunctive Relief, Airbnb, Inc. v. City and Cty. of San Francisco, No. 3:16-cv-03615-JD (N.D. Cal. June 27, 2016), ECF 1.

195 Airbnb, Inc. v. City \& Cty. of San Francisco, 217 F. Supp. 3d 1066, 1070 (N.D. Cal. 2016). This action by the Board of Supervisors to impose liability based on an action by the platforms, i.e., the collection of a booking fee, was a clever way to circumvent the protections the CDA provides for content posted on the Internet.

${ }^{196}$ Id. at 1071. The 20-year-old Communications Decency Act was written to protect Internet providers from being responsible for content posted by users. Id. at 1074 ("Congress enacted Section 230 primarily 'to protect websites against the evil of liability for failure to remove offensive content."') (quoting Fair Hous. Council v. Roommates.com, 521 F.3d 1157, 1174 (9th Cir. 2008)).

${ }^{197}$ See id. at 1071-72. See also Jack Segal, Airbnb and the End of the Short-Term Rental War [BeaconExplains], BAY CITY BEACON (June 14, 2017), https://www.thebaycitybeacon.c om/politics/airbnb-and-the-end-of-the-short-term-rental-war/article_623e8b6a-511b-11e7-

8ad3-e3ce6bea0cf8.html [https://perma.cc/Z4N4-PLFU] (describing the history of the 2016 lawsuit).

${ }^{198}$ See Nathan Ingraham, New York Passes Law Making it Illegal to List Short-Term Rentals on Airbnb, ENGADGET (Oct. 21, 2016), https://www.engadget.com/2016/10/21/new-yorkpasses-law-making-it-illegal-to-list-short-term-rentals/ [https://perma.cc/AB7P-N5GG]. 
subjecting Airbnb itself to the fines of up to $\$ 7,500$ per violation. ${ }^{199}$ Within hours, Airbnb filed a lawsuit alleging that the new law violated its constitutional rights on much the same grounds it used in its lawsuit against the city of San Francisco. ${ }^{200}$

In November of 2016, the judge in the San Francisco case ruled that it was unlikely that Airbnb would prevail on the merits of its claims. ${ }^{201}$ Carefully distinguishing prior cases under the Communications Decency Act, the court found that the San Francisco law was not imposing liability on Airbnb for its role as a content publisher, but for its conduct in taking a fee for the booking of an unregistered listing. ${ }^{202}$ The court also found that Airbnb had not met the standards for First Amendment scrutiny or those for contesting the imposition of criminal liability. ${ }^{203}$

Airbnb quickly recognized that it had its back against a wall. In the week following the judge's ruling, Chris Lehane, Airbnb's Global Head of Policy, wrote an op-ed in the San Francisco Chronicle stating that the company was ready to cooperate with city officials to create a simplified registration system that would share information about hosts' listings and rentals with the city. ${ }^{204}$ By the beginning of December, the company had also settled with the state of New York. ${ }^{205}$

\footnotetext{
${ }^{199} I d$

${ }^{200}$ Katie Benner, Airbnb Sues Over New Law Regulating New York Rentals, N.Y. TiMES (Oct. 21, 2016), https://www.nytimes.com/2016/10/22/technology/new-york-passes-lawairbnb.html [https://nyti.ms/2kqvvlv] ("[T] he company contends that the law violates the company's constitutional rights to free speech and due process, as well as the protection it is afforded under the Communications Decency Act.").

${ }^{201}$ Carolyn Said, Airbnb Rebuked in SF Lawsuit, S.F. GATE (Nov. 8, 2016, 5:11 PM), http://www.sfgate.com/business/article/Airbnb-rebuked-in-SF-lawsuit-10602042.php

[https://perma.cc/L79T-T6SA].

${ }^{202}$ See Airbnb, Inc. v. City \& Cty. of San Francisco, 217 F. Supp. 3d at 1073-76.

${ }^{203} \mathrm{Id}$. at $1076-80$.

${ }^{204}$ Chris Lehane, How Airbnb, SF Can Help Hosts Meet City's Rules, S.F. CHRONICLE (Nov. 13, 2016), http://www.sfchronicle.com/opinion/openforum/article/How-Airbnb-SF-can-helphosts-meet-city-s-rules-10611714.php [https://perma.cc/YR2J-9U3Q]. On May 1, 2017, Airbnb and the city of San Francisco announced they had reached a settlement. Herrera Repels Legal Challenge to Short-Term Rental Law, Secures Settlement with Airbnb and Homeaway, CITY ATT'Y S.F. (May 1, 2017), https://www.sfcityattorney.org/2017/05/01/herre ra-repels-legal-challenge-short-term-rental-law-secures-settlement-airbnb-homeaway/ [https://perma.cc/VAC9-M7XT]. Airbnb agreed to a process that would ensure its users are registered with the city before their listings can be booked on the platform and to share data
} 
Airbnb has spent money, time and effort battling regulators and their harsh penalties for six years. Nevertheless, the company recognized that an attitude of defiance was no longer serving its interests. ${ }^{206}$ The bad publicity and aura of regulatory uncertainty from its continued battles with lawmakers was affecting the company's valuation at either future funding rounds or an IPO ${ }^{207}$ Perhaps if the regulators in New York and San Francisco had a more collaborative process for working with Airbnb when it first began to operate, everyone would have been better off.

In this section, we demonstrated that traditional regulatory processes cause escalating tension between innovative companies and rule makers. In pursuit of their goals of consumer safety and economic growth, regulators are most likely to use antiquated enforcement mechanisms as the basis for their initial interactions with new entrants to the industry. ${ }^{208}$ In response, companies like Uber and Airbnb use their financial resources, large customer base, and continually evolving technology to avoid complying with rules they did not

on its hosts with the city on a regular basis. Id. Airbnb remains criminally liable if it fails to do so. See S.F. ADMIN. CoDE $§ 41$ A.5(e) (2017).

${ }^{205}$ Katie Benner, Airbnb Ends Fight with New York City over Fines, N.Y. Times (Dec. 3, 2016), https://www.nytimes.com/2016/12/03/technology/airbnb-ends-fight-with-new-yorkcity-over-fines.html [https://nyti.ms/2ktJG9n].

${ }^{206}$ See As Airbnb De-Escalates Legal Fight with Regulators, What's Next?, INVESTORS Bus. DAILY (Dec. 8, 2016), http://www.investors.com/news/as-airbnb-de-escalates-legal-fightwith-regulators-whats-next/ [https://perma.cc/3M7N-B3QQ] (describing Airbnb's transition form a "bare-knuckles approach" to starting to get along with regulators); see also Mike Isaac, Airbnb Pledges to Work with Cities and Pay 'Fair Share' of Taxes, N.Y. TIMES (Nov. 11, 2015), https://www.nytimes.com/2015/11/12/technology/airbnb-pledges-to-work-with-citiesand-pay-fair-share-of-taxes.html [https://nyti.ms/2mVTpq1]. Airbnb's company culture lends itself to cooperation more than that of Uber. Its motto, "Be a Host," may have opened doors to cooperation. See supra text accompanying note 130.

207 See Kia Kokalitcheva, Airbnb Changes Its Tune in New York, ForTunE (Dec. 6, 2016), http://fortune.com/2016/12/06/airbnb-drops-ny-lawsuit/ [https://perma.cc/6ML4-SZCC].

${ }^{208}$ Innovation has occurred in many industries, and as a result, regulators have been hardpressed to apply old regulation to new business models. Just as with regulators like the CPUC and the TLC, other regulators have been given broad authority over the industries they administer but their mechanisms are less and less fit for the job. See Stephanie Forshee, CFTC Announces Innovation Lab for Fintechs, NAT'L L.J. (May 17, 2017), http://www.nationallawjournal.com/id=1202786468443/CFTC-Announces-Innovation-Labfor-Fintechs [https://perma.cc/GA3G-C8JJ] (quoting CFTC Acting Chairman J. Christopher Giancarlo saying "[t]he world is changing. Our parents" financial markets are gone. . . Y Yet, despite these 21 st century innovations, the CFTC remains stuck in a 20th century time warp."). 
believe applied to them. Ultimately, both sides compromised to some extent, but there was a great deal of time, money, and effort expended by every participant to get to that result. In Part III, we suggest a change in regulatory procedures so that similar losses do not occur when the next innovative business appears.

\section{AN ALTERnAtive METHOD FOR ALtERnATIVE RULEMAKING}

In the spirit of innovation, this paper posits a different method for rulemaking that may yield more positive results for regulators as well as innovators. The process we suggest is adapted from research and design labs around the world, and is called design thinking. Design thinking offers a modern organization or bureaucracy a means to cultivate creativity and innovation. ${ }^{209}$ It has been said that the success rate for innovation dramatically improves when design principles are used to achieve it. ${ }^{210}$

\section{A. What is Design Thinking?}

Design thinking is a solution-focused method that begins by identifying a goal instead of a problem. In this way, the process encourages an action-oriented approach and uses "logic, imagination, intuition and systemic reasoning . . . to create desired outcomes. ${ }^{, 211}$ Design thinking is also usercentric and thus requires an examination of the needs, experiences, and viewpoints of the user.

${ }^{209}$ What Is Design Thinking?, DeSIGN MGMT InST., http://www.dmi.org/?WhatisDesignThink [https://perma.cc/KU76-NAUQ]; see also Michael T. McHugh, Driving Government Transformation Through Design Thinking, FED. TIMES (Aug. 24, 2016), https://www.federaltimes.com/opinions/2016/08/24/driving-government-transformation-

through-design-thinking/ [https://perma.cc/V4NQ-DXT3] ("federal agencies are beginning to use design thinking to creatively address mission objectives and improve processes").

${ }^{210}$ See Linda Naiman, Design Thinking as a Strategy for Innovation, CREATIVITY AT WORK, https://www.creativityatwork.com/design-thinking-strategy-for-innovation/

[https://perma.cc/5XCC-GT48] (citing a 2014 study by the Design Management Institute to state that "[d] esign-led companies such as Apple, Coca-Cola, IBM, Nike, Procter \& Gamble and Whirlpool have outperformed the S\&P 500 over the past 10 years by an extraordinary $219 \% ")$.

${ }^{211}$ This description is drawn from a more expansive discussion of the attributes of design thinking. See Armitage, supra note 30, at 34-41; see also Naiman, supra note 213. 
The design-thinking process involves successive steps, each of which utilizes input from all stakeholders to forge workable solutions. The best solutions are identified and then tested through experimentation with actual users in real-world situations. The feedback gained from those users is then utilized to redesign the possible solutions, with the resulting versions again sent out for testing. These successive feedback loops are reminiscent of the iterative cycles of agile product development, and help in the same way to quickly generate the information necessary to create the best possible results. $^{2}$

The specific steps of design thinking are as follows:

- Identify the problem to solve

- Identify the stakeholders, who then set their individual goals (divergent thinking) ${ }^{213}$

- Convene to brainstorm solutions with all stakeholders participating (convergent thinking) $)^{214}$

- Choose and implement best solutions

- Solicit stakeholder feedback

- Revise and retest solutions

- Continue with feedback loops until the most appropriate solution has been reached

- Release the most appropriate solution to a small segment of the public in a beta test

- Iterate process again based on data from beta tests

- Test again and collect feedback

- Continue process when necessary to adapt to new innovations

${ }^{212}$ See Lohr, supra note 57.

${ }^{213}$ Divergent thinking - the process by which each stakeholder individually determines its own goals for the project-is an important part of design thinking because it ensures the integrity of each stakeholder's specific goal. Goal setting is an important part of the design thinking process because it allows stakeholders to envision their ideal situation prior to making any outside considerations.

${ }^{214}$ Divergent thinking is a vital part of the beginning of the design thinking process. Convergent thinking, during which the group as a whole examines the individual goals of each stakeholder, is at the crux of this method's efficacy. Stakeholders must come together to discuss all the viewpoints they each must take into account in creating a solution. 
While design thinking may not be a panacea for every issue that plagues regulatory agencies, its emphasis on innovation and collaboration helps to facilitate open communication with entrepreneurs and the companies they build.

\section{B. Design Thinking in the Private Sector}

It is tempting to dismiss this agile and flexible process as relevant only to the sorts of teams that meet in co-working spaces in Silicon Valley. This collaborative method, however, is already making an impact in reimagining systems in various corporate sectors.

For example, Kaiser Permanente hired innovation lab IDEO to help them rethink the processes Kaiser uses to manage patient care. The goal was to diminish medical errors and oversights while improving overall efficiency and return on investment. ${ }^{215}$ IDEO convinced Kaiser to include all levels of management in the process because successful innovation cannot occur in a vacuum. ${ }^{216}$ Members of the Kaiser Permanente Innovation Team spent long periods of time observing nurses and going through the design thinking steps. ${ }^{217}$ Ultimately, IDEO and Kaiser designed a new program called the Nurse Knowledge Exchange. ${ }^{218}$ This program has lowered costs by $47 \%$ and is now operating in every Kaiser Permanente hospital. ${ }^{219}$

We posit that the same stakeholder-focused, collaborative process that Kaiser Permanente used for this successful innovation could also be implemented by governmental agencies in the regulatory process. ${ }^{220}$ Regulators currently rely on punitive measures to achieve their goals of

${ }^{215}$ See Lew McCreary, Kaiser Permanente's Innovation on the Front Line, HARV. BuS. REV. (Sept. 2010), https://hbr.org/2010/09/kaiser-permanentes-innovation-on-the-front-lines [https://perma.cc/6KVW-GXR4].

${ }^{216} \mathrm{Id}$.

${ }^{217} \mathrm{Id}$.

${ }^{218} I d$.

${ }^{219}$ Id.

${ }^{220}$ Collaborative rule making that follows many of the design thinking steps-including iterative development - has been successful in some government agencies already. See, e.g., Forshee, supra note 208 ("By engaging with FinTech, we will learn where the friction points are between innovation and our regulations," [CFTC Acting Chairman] Giancarlo said. "As we meet with more and more innovators, we can expect to see patterns emerge - to see which rules come up time and time again as the most problematic, the least able to adapt to evolving technologies.”). 
consumer safety, environmental health, and positive economic expansion. ${ }^{221}$ But, as we explained in Part II, technology is developing so rapidly that companies can have programs or business models up and running long before regulators learn of their existence. For example, Uber created and used Greyball - a program that allowed it to evade law enforcement in cities where the platform company was under review-for three years before regulators discovered its existence. ${ }^{22}$ By utilizing design-thinking principles in the regulatory process, as behemoth private companies like Kaiser have done, rule makers will have an appropriate tool to meet the changing industries they regulate. ${ }^{223}$

The application of the design-thinking framework to the regulatory process can manifest itself in a number of different ways, but the most important functions must remain consistent:

- The problem the rule is intended to address is identified

- The relevant stakeholders identify their individual goals for new regulation $^{224}$

- The stakeholders then meet to brainstorm solutions for the identified problem

- The best solutions are chosen, often by a smaller working group, and a regulation is designed that implements these solutions

- The initial regulation is presented to stakeholders, and feedback is solicited

- The stakeholders then revise their agreed-upon solutions and retest them to make sure they address the identified problem

221 See examples of punitive measures that California regulators and New York City regulators use, see generally Part II.

${ }^{222}$ Greyball allowed Uber drivers to evade regulators attempting to ticket them for using the service illegally in Portland, Oregon. The program was in use across the United States from 2014 to 2017. It was only brought to the authorities' attention in 2014. See Isaac, supra note 139.

${ }^{223}$ See generally Armitage, supra note 30. For a description of design thinking as used to rethink the regulation of transportation and accommodation in Toronto, see MARS SOLUTION LAB, ShifTing Perspectives: Redesigning REgulation FOR THE SHARING ECONOMY (Mar. 2016), https://www.marsdd.com/wp-content/uploads/2016/04/MSL-Sharing-EconomyPublic-Design-Report.pdf [https://perma.cc/M3GE-K298] ("The Sharing Economy Public Design project, a partnership between MaRS Solutions Lab, the Province of Ontario and the City of Toronto, applies a design perspective to this complex problem").

${ }^{224}$ See infra text accompanying note 229 for an example of the identification of stakeholders. 
- These feedback loops continue until the most appropriate regulation is produced

- The new regulation is then tested in a smaller segment of the relevant population in what is called a "beta test"

- Feedback is solicited from the beta test users

- This beta test will return new information to consider and the stakeholders will revise the regulation

- This process continues until the regulation best addresses problems identified

- Feedback loops remain open so that regulation can be easily amended to account for new problems and new stakeholders

\section{Applying Design Thinking to the Regulatory Process}

Design thinking involves a nonlinear way of thinking and requires real-world experimentation. ${ }^{225}$ The team chosen to undertake the process together should be interdisciplinary and all should have the capacity and disposition to think collaboratively. ${ }^{226}$ Unlike a multidisciplinary team in which each person advocates for his or her own position, an interdisciplinary team focuses on a collective ownership of ideas for which everyone takes responsibility. ${ }^{227}$ "In its simplest form, design thinking is a processapplicable to all walks of life-of creating new and innovative ideas and solving problems." 228

\section{Identify the Stakeholders}

The underlying tenet of design thinking is that everyone affected or involved in the use of that which is being designed should participate in the

\footnotetext{
225 See, e.g., Naiman, supra note 213 ("Methods for thinking like a designer include observing, interviewing, creating personas, empathy mapping, storyboards, associational thinking, creating low-tech prototypes, and decision-making analysis.").

${ }^{226}$ See generally TIM BROWN, CHANGE BY DESIGN (2009).

${ }^{227} \mathrm{Id}$.

${ }^{228}$ Kaan Turnali, What Is Design Thinking?, FORBES (May 10, 2015), http://www.forbes.com/sites/sap/2015/05/10/what-is-design-thinking/\#30147b7d3c18

[https://perma.cc/MR8J-QTNL]; design thinking has also been used as the basis for making personal decisions. See generally BILl BARNETt \& DAlE Evans, Designing Your LifE (2016).
} 
design process. For example, for the creation of regulations for the ridesharing industry, the following stakeholders could be identified as having an interest in the eventual rule: $:^{229}$

- Ride-sharing companies

- Car-sharing companies

- Rental-car companies

- Taxi companies

- Local regulators

- Public-transit systems

- Airport representatives

- City planners

- Environmental-impact experts

- Consumers

\section{Stakeholders Convene and Decide the Goals and Public Value of Specific}

\section{Regulation}

Public value includes not only consumer protection, fair competition, and accessibility for all potential consumers, but also the social good that comes from the availability of the innovative service or product the new entrants to the industry provide. ${ }^{230}$ With design thinking, all stakeholders work together to identify the public value of a specific area of regulation. For example, taxi companies might identify the public value of regulations in the pay-for-a-ride space as leveling the playing field for all participants in the market. City planners and environmental experts might see the value of the

${ }^{229}$ This list is based on the stakeholders identified in the MaRS Solution Lab report undertaken for the city of Toronto. See MARS, supra note 223.

${ }^{230}$ In a design thinking process for regulation, all stakeholders would be asked to consider the public value of what they would want the regulation to achieve. See id. at 21 ("[d]esigning effective regulation involves solving a trilemma: public value, administration and innovation."); Cf. Shayne Kavanagh, "Defining and Creating Public Value”, Gov. FINANCE REV., 57, 60 (2014), http://www.gfoa.org/sites/default/files/GFROct1457_0.pdf

[https://perma.cc/BG53-7ZSH] (explaining how Mark Moore developed the concept of public value to ask public officials to consider the benefits and costs of public services not only in terms of dollars and cents, but also in terms of how government actions affect important civic and democratic principles such as equity, liberty, responsiveness, transparency, participation, and citizenship). 
data the companies would be required to share on the number and locations of rides given, which would help them improve their estimates for future plans and impacts. A new entrant to the market might favor regulations because there would be a straightforward, user-friendly process of complying. Alternatively, an entrant might ask for modifications to fit its specific business model. Regulators might favor being an educated, engaged, and respected part of the process of making the industry competitive, safe, and valuable to the public at large. ${ }^{231}$

\section{$\underline{\text { 3. Stakeholders Brainstorm Possible Solutions }}$}

Stakeholders should first separately identify solutions and then bring them to a brainstorming session with everyone together. ${ }^{232}$ The first half of this, the independent brainstorming, utilizes divergent thinking, while the second half, collaborating with others to create more broadly based solutions, is called convergent thinking. ${ }^{233}$

\section{Stakeholders Identify a Few Best Solutions and Implement Them}

This implementation process is essentially a short-term pilot or experiment in which the best regulations are put to use for a set period of time. ${ }^{234}$ This part of the process could be referred to as a "sandbox" in which ideas can be tried out and quickly eliminated or redesigned. At this point, a smaller working group may be identified if not all stakeholders can devote the time and energy this requires.

\section{Solicit Feedback from Users}

In the case of a pilot regulation, the regulation would not just be published as a proposed rule, but would be immediately implemented.

\footnotetext{
${ }^{231}$ For the words of a regulator instituting this sort of process, see Forshee, supra note 208.

${ }^{232}$ See Art Markman, Your Team Is Brainstorming All Wrong, HARV. Bus. REV. (May 18, 2017), https://hbr.org/2017/05/your-team-is-brainstorming-all-wrong [https://perma.cc/3MRJWWGF].

${ }^{233}$ Id.

${ }^{234}$ An Introduction to Design Thinking: A Process Guide, HASSO PlATTNER INST. DESIGN AT STAN., https://dschool-old.stanford.edu/sandbox/groups/designresources/wiki/36873/attachme nts/74b3d/ModeGuideBOOTCAMP2010L.pdf [https://perma.cc/MUC5-8U28].
} 
Feedback would be solicited within a month or two from the companies operating under the regulation, as well as from users and other stakeholders impacted by the experimental regulation. This process is shorter and more informal than the current extended comment period of proposed rules and feedback is based not just on theoretical objections, but on experiences operating under the rules.

\section{$\underline{\text { 6. Stakeholders Revise Solutions and Test Again }}$}

Based on user feedback and with input from all stakeholders, the pilot regulation is revised and implemented for another testing period.

\section{Solicit Feedback Again}

Once again feedback is based on how the rules are working in the realworld.

\section{Feedback Loops Continue Until an MVP Is Agreed Upon}

The Minimum Viable Product (MVP) is still an early version that will have ongoing feedback loops, but has met the minimum standards of the stakeholders and so is released to the public to be more widely used and tested.

\section{New Process Allows Continuous Tweaking}

For a regulatory process to be truly nimble and flexible, there will have to be ways for users and stakeholders to engage with regulators on a regular basis and work together to modify rules so that they are in line with changes in technology and the marketplace.

\section{These Steps Must Be Repeated for Each Industry}

This is not a one-size-fits-all process. The stakeholders, the public value, and the users will vary from one industry to another as will the regulations.

What are the foreseeable problems in bringing design thinking to the regulatory process? Possible trouble areas include: 
- Getting startups to the table

- Incentivizing regulators to participate

- Identifying the correct stakeholders

- Prototyping and effectively iterating regulations

- Providing sufficient time for testing without making the process too slow

- Designing metrics that adequately summarize the impact the tested regulations are having on various stakeholders like the companies using them, the regulators enforcing them, and the public using the new product or service ${ }^{235}$

Ideally, applying design thinking to the regulatory process will transform the regulatory system. Under this system, agencies may be less prone to regulatory capture ${ }^{236}$ because rather than enforcing stagnant rules available for manipulation, they create and adapt living documents, more easily amenable to change.

\section{How Implementation of Design Thinking Could Address Harms Caused by Culture Clash}

As described in Part II, regulators were often playing catch up to Uber and Airbnb as the innovative business models evolved and the companies' use of technology pivoted. Regulator's limited access to resources, along with the inherent nature of traditional bureaucratic processes, curbed their ability to address new challenges brought about by innovation. Yet, despite this, regulators and innovative companies share a common goal: expanding access through transportation and accommodation. Unfortunately, the initial negative interactions pitted the regulators against the platform companies, and muddled any opportunity to recognize these commonalities. Overall, each stakeholder impacted by the emergence of Uber and Airbnb incurred harms that arose during the regulatory battles.

\footnotetext{
${ }^{235}$ For some solutions to these possible issues, see generally Armitage, supra note 30, at 3134.

${ }^{236}$ See Stigler, supra note 37. The ongoing nature of the proposed feedback loops should help mitigate any threat of regulatory capture. A possibility of regulatory capture in the designthinking framework may remain, especially because regulators will spend more time interacting in preliminary phases with innovative new companies.
} 
Design thinking has the potential to alleviate these harms. Below, we posit how the design-thinking framework could alter outcomes for all stakeholders:

\section{$\underline{\text { 1. To Citizens }}$}

The present regulatory system harms the public by not providing a method by which citizens can be protected while innovative companies test their products with early adopters. ${ }^{237}$ The iterative steps in a design-thinkingbased regulatory process would allow regulators to issue temporary safety rules and assign liability while products and services are in the beta-testing stage. The beta test itself could be limited by restricting the number of users to reduce the extent of potential harms. In this new process, stakeholders would convene regularly throughout the technology's life cycle to reevaluate it. In addition, regular communication and collaboration may allow regulators to anticipate harms before they arise, and platform companies to address larger crises before they occur. ${ }^{238}$

${ }^{237}$ Consumer harms caused by Uber's entry into the market are well documented. See Rob Lieber, Airbnb Horror Story Points to Need for Precautions, N.Y. TIMES (Aug. 14, 2015), https://www.nytimes.com/2015/08/15/your-money/airbnb-horror-story-points-to-need-forprecautions.html [https://perma.cc/F64N-GYJL] (discussing the sexual assault and attempted murder of an American student in an Airbnb in Madrid); see also Kale Williams \& Curtis Alexander, Uber Sued Over Girl's Death in S.F., S.F. GATE (Jan. 28, 2014), http://www.sfgate.com/bayarea/article/Uber-sued-over-girl-s-death-in-S-F-5178921.php [https://perma.cc/EL4A-PFHE] (discussing how an Uber driver struck a young girl in a hit and run accident in a San Francisco neighborhood); Niamh McIntire, Uber London Ban: The Scandals That Brought Down the Ride Hailing App, INDEPENDENT (Sept. 22, 2017), http://www.independent.co.uk/news/uk/home-news/uber-london-ban-latest-news-scandalsrape-women-sexual-assault-ride-hailing-app-tfl-india-a7961236.html [https://perma.cc/GEQ5J9C4] (discussing Uber's widely publicized rape case in Delhi, India — one of the issues that led to the Uber ban in London). The term "early adopter" is well-known in the technology community and refers to the first small group of users who are eager to try out new innovations being tested in the marketplace for proof of concept and viability. Brian Kennedy and Cary Funk, 28\% of Americans are 'Strong' Early Adopters of Technology, PEW RES. CTR (July 12, 2016), http://www.pewresearch.org/fact-tank/2016/07/12/28-of-americans-arestrong-early-adopters-of-technology/ [https://perma.cc/C3JN-MD4E].

${ }^{238}$ If company data-for example, indicating the most highly used drop-off locations for early-morning ridesharing - was shared with regulators, municipal officials might recognize that to ease traffic congestion, traffic light automation patterns needed to be altered. Or, if certain neighborhoods draw most home-sharing bookings, regulators might decide to limit the 


\section{To Cities}

Both Airbnb and Uber have disrupted large incumbent industries and, in doing so, have fundamentally changed the way cities function. For example, public transit systems have been impacted by the significant portion of citizens who now rely on ride sharing companies as their primary method of transportation. ${ }^{239}$ Similarly, consumers rely on Airbnb as an affordable alternative to costly hotels. As a result, both platform companies have had unforeseen effects on the city's economy, ecosystem, and environment, such as pressure on the real estate market, increased traffic, diminished air quality, ${ }^{240}$ and increased signs of wealth inequality. ${ }^{241}$ In a regulatory process that follows the design thinking method, the inclusion of all stakeholders increases the likelihood that these sorts of potential impacts will be identified early in the process. The collaborative aspects of design thinking methods could also facilitate data sharing between platform companies and regulators

number of listings available in that area to maintain the character of the neighborhood for its residents.

${ }^{239}$ Mary Wisnewski, Ride-Sharing Services Like Uber Cutting Into Public Transit Use in Chicago, Elsewhere: Study, CHI. TRIB. (Oct. 19, 2017), http://www.chicagotribune.com/news/ local/breaking/ct-met-ride-hailing-survey-20171016-story.html [https://perma.cc/4DARH8LF]. In some locations, ridesharing has become a valuable option for the daily commute. For example, in the fall of 2017, in San Francisco, a Lyft line can sometimes cost only $\$ 1.25$ more than taking the bus (based on tests conducted by the authors). While this is more expensive, riders might consider it "worth it" for speed, comfort, and reliability.

${ }^{240}$ See Kate Gilbraith, Are Uber and Lyft Helping or Hurting the Environment, GUARDIAN (Jan. 21, 2016), https://www.theguardian.com/environment/2016/jan/21/uber-lyft-helpinghurting-environment-climate-change [https://perma.cc/ZQM8-X8EK]; see also Doug Tribou, In the Age of Airbnb, Michigan Beach Towns Try to Balance Renters and Residents, MicH. RADIO (Apr. 28, 2017), http://michiganradio.org/post/age-airbnb-michigan-beach-towns-trybalance-renters-and-residents [https://perma.cc/L5UN-FJTG]. For impacts to the economy, see Fawn Johnson, How Airbnb and Uber are Changing the Nature of Work, ATLANTIC (Nov. 13, 2014), https://www.theatlantic.com/business/archive/2014/11/how-airbnb-and-uber-arechanging-the-nature-of-work/425402/ [https://perma.cc/4RPA-RBCE]; see also Nathan Heller, Is the Gig-Economy Working? Many Liberals Have Embraced the Gig Economy. But Can They Survive It?, NEW YORKER (May 15, 2017), http://www.newyorker.com/magazine/2 017/05/15/is-the-gig-economy-working [https://perma.cc/DB8U-LJ8D].

${ }^{241}$ See Keith Parkins, The Secret to the Uber Economy Is Wealth Inequality, MEDIUM (Dec. 15, 2014), https://medium.com/dark-mountain/the-secret-to-the-uber-economy-is-wealthinequality-800859791a91 [https://perma.cc/EBZ2-AQYM]. 
without resorting to the costly lawsuits described in Part II. ${ }^{242}$ In this way, a process that mandates collaboration early on could turn regulations into mechanisms that meet the diverse goals of urban planners, politicians, law enforcement, and platform companies.

\section{$\underline{\text { 3. To Micro-Entrepreneurs }}^{243}$}

In 2014, Airbnb CEO Brian Chesky aptly noted that the rise of platform companies created a third category of commercial activity-one that describes people in their individual capacity functioning like businesses. ${ }^{244}$ Initially, drivers and hosts bore all the costs for the services they provided through Uber and Airbnb; the press is full of stories of guests trashing Airbnb

${ }^{242}$ Cf. Stephen Melendez, Sharing Economy Giants Are Using Data To Build "The Taking
Economy," Study Warns, FAST COMPANY (Mar. 14, 2017), https://www.fastcompany.com/3068881/sharing-economy-taking-economy-uber-airbnb-dataasymmetry-study [https://perma.cc/78DS-9Y22] (describing how companies like Uber and Airbnb are the only ones in possession of data that regulators need, stating that "it's likely that some innovation and experimentation will be required on the part of regulators, too, to find the best way to find and address potential abuses by sharing-economy companies"); Ryan Calo \& Alex Rosenblat, The Taking Economy: Uber, Information, and Power, 117 ColuM. L. REV. 1623 (2017) (advocating for the use of consumer protection laws to address "the asymmetries of information" in the sharing economy).

${ }^{243}$ The individuals providing services through the platform companies are often called micro entrepreneurs. See Armitage, supra note 30, at 11; see also Andy Kessler, Brian Chesky: The 'Sharing Economy' and Its Enemies, WALL ST. J. (Jan. 17, 2014), http://www.wsj.com/articles/SB10001424052702304049704579321001856708992 (quoting Brian Chesky: "I want to live in a world where people can become entrepreneurs or microentrepreneurs"). The concept of micro-entrepreneurs arose as a result of the business models of Uber, Airbnb, and other platform companies. These companies have taken the position that those individuals who provide the services offered through their technology are not their employees, but instead are independent contractors simply using the platform to connect with those who would like to utilize their services. See generally Benjamin Means \& Joseph Seiner, Navigating the Uber Economy, 49 U.C. DAVIS L. REV. 1511 (2016); see also Keith Cunningham-Parmeter, From Amazon to Uber: Defining Employment in the Modern Economy, 19 B.U.L. REV. 1673 (2016).

${ }^{244}$ This distinction between employee and independent contractor remains controversial, and is currently the subject of considerable litigation with many of the platform companies. In the summer of 2017, Uber was embroiled in a costly class-action over fares with drivers. See David Streitfield, Uber Drivers Win Preliminary Class Action Status in Labor Case, N.Y. TIMES (July 12, 2017), https://www.nytimes.com/2017/07/12/business/uber-drivers-classaction.html?_r=0 [https://perma.cc/4RDM-VWUV]. 
rentals and passengers damaging the backseats of the cars belonging to their Uber drivers. $^{245}$

The platform companies are able to collect considerable amounts of data on where and when the micro-entrepreneurs on their platforms are providing services. ${ }^{246}$ This data is valuable to regulators and other government officials as a means of understanding and predicting how to make their localities function better for their citizenry. ${ }^{247}$ As was made clear in the regulatory battles of Uber and Airbnb described in Part II, the platform companies are reluctant to share this data, claiming that the privacy of their users is at issue. ${ }^{248}$ As part of the settlements that Airbnb eventually reached with the state of New York and the city of San Francisco, the company agreed to share some of its data with regulators. Uber has agreed to share some aspects of its data, but not all. ${ }^{249}$

${ }^{245}$ In one nightmare-inducing story that made headlines, a home in Calgary Canada was destroyed after an Airbnb guest threw a party. Airbnb did not provide compensation to the hosts. Olivia Waxman, This House Was Totally Trashed After Being Rented on Airbnb, TIME (Apr. 30, 2015), http://time.com/3841703/airbnb-calgary/ [https://perma.cc/H6B5-T9N8].

${ }^{246}$ Airbnb collects data from its hosts, but there is little published on the exact extent of that data collection. See Kim-Mai Cutler, Airbnb and the Problem of Data, TeCHCRUNCH (June 11, 2015), https://techcrunch.com/2015/06/11/airbnb-and-the-problem-of-data/ [https://perma.cc/B8EZ-P5MM]. Uber also collects data from its riders and drivers, often through controversial programs. See supra text accompanying note 130; see also How Uber Uses Data to Improve Their Service and Create the New Wave of Mobility, KISSMETRICS, https://blog.kissmetrics.com/how-uber-uses-data/ [https://perma.cc/8S9E-ET3L].

${ }^{247}$ Airbnb already shares their data with cities. See Meghan Rose Dickey, Airbnb Settles Lawsuits with San Francisco, TECHCRUNCH (May 1, 2017), https://techcrunch.com/2017/05/01/airbnb-settles-lawsuit-with-san-francisco/

[https://perma.cc/2VQ3-ABZB]. Uber has been sharing some traffic data with city planners since January 2017. See Mike Isaac, Uber Extends Olive Branch to Cities, N.Y. TIMES (Jan. 8, 2017), https://www.nytimes.com/2017/01/08/technology/uber-movement-traffic-data.html [https://perma.cc/65B2-BGMY].

${ }^{248}$ See supra text accompanying note 79 and citations referenced therein.

${ }^{249}$ While Uber's open source data set will be valuable to urban planners (see Isaac, supra note 247), Uber is not likely to start sharing rider or driver data with governments. Unlike Airbnb, all of Uber's data is anonymous. See John Riberio, Uber Offers Cities 'Anonymized' Ride Data, PCWORLD (Jan. 9, 2017), https://www.pcworld.com/article/3155494/techologybusiness/uber-to-provide-anonymized-data-to-city-officials.html [https://perma.cc/2EVHP7NN]. There is a major privacy concern with ride sharing platforms' data collection; Cheryl Miller, Uber and Lyft Resist California Regulators' Appeal for Data Sharing, LEGAL TECH News (Oct. 11, 2017), https://www.law.com/legaltechnews/almID/1202800136629 [https://perma.cc/22W3-8HU2]. 
In a design-thinking-based regulatory process, data sharing would no doubt be one of the aspects of the early solutions offered in return for regulations that enabled new innovative businesses to operate, both in betatesting phases as well as long-term. This kind of early collaboration would avoid the expenses wasted on confrontations that eventually resulted in exactly this sort of data-sharing, and could also address some of the privacy concerns that the micro-entrepreneurs have voiced in these battles. ${ }^{250}$ With early beta-testing data, both regulators and innovators would be better able to see how consumers, micro-entrepreneurs, and others were at risk from this new business, and could collaborate on how regulation could allocate or protect against those risks.

\section{To Platform Companies}

In Part II, we examined the costly battles Uber and Airbnb have waged around the world. In mid-2016 Uber was fighting more than 70 lawsuits in U.S. federal court. ${ }^{251}$ Those costs are likely to continue until Uber is more willing to compromise with regulators. ${ }^{252}$ In some cities-notably Vancouver and Austin-Uber has been banned for good. ${ }^{253}$ Airbnb has suffered a ban in the major market of New York and a faced legislative attack in San Francisco. ${ }^{254}$ Further, after spending countless hours and an exorbitant amount of money fighting required data-sharing with San Francisco regulators, Airbnb not only agreed to share data from its platform but also accepted the potential

\footnotetext{
${ }^{250}$ See Miller, supra note 249. Airbnb's concerns about user privacy largely fueled the battle it waged with rule makers in a number of locales, including Los Angeles. See Melanie Mason, Citing Privacy Concerns, Airbnb Slams Bill on Short-Term Rentals, L.A. TIMES, (Apr. 21, 2015), http://www.latimes.com/local/political/la-me-pc-airbnb-legislation-20150421story.html [https://perma.cc/PA6L-W7LG].

${ }^{251}$ Marisa Kendall, Uber Battling More than 70 Lawsuits in Federal Courts, MERCURY NEWS (Aug. 11, 2016), http://www.mercurynews.com/2016/07/04/uber-battling-more-than-70lawsuits-in-federal-courts/ [https://perma.cc/9CD7-2ZAT] (giving details of lawsuits and settlements in 2015-16).

${ }^{252} I d$. (detailing antitrust claims against Uber in New York over price-fixing that could be worth $\$ 1$ billion).

${ }^{253}$ Ryan Craggs, Where Uber is Banned Around the World, CONDÉ NAST TRAVELLER (Apr. 15, 2017), https://www.cntraveler.com/story/where-uber-is-banned-around-the-world [perma.cc/M2DH-2UTP]; see also Nibler, supra note 162 (Uber banned from operating in London due to deceptive practices).

${ }^{254}$ Craggs, supra note 253.
} 
for criminal liability should it fail to comply with regulation. ${ }^{255}$ Criminal liability was not mentioned prior to Airbnb's resistance to San Francisco's 2015 regulations that required data sharing. Arguably the city would not have created, nor Airbnb accepted, such a severe penalty if collaboration had begun earlier.

The companies in our case study burned through investment dollars and revenue in their regulatory battles, ${ }^{256}$ were distracted from growing their businesses in competitive markets, ${ }^{257}$ and lost investor confidence-an important asset for a pre-IPO company. ${ }^{258} \mathrm{~A}$ design-thinking-based regulation process would make these harsh punitive measures (such as cease-and-desist letters, fines, and litigation) a final option instead of an initial contact, and would provide regulators with the most appropriate tools available to meet their goals. In addition, this process would allow platform companies to make functional changes to their products without public relations crises because regulators and innovators would convene regularly as markets and technology changed.

A collaborative and iterative process that enables regulators and innovators to communicate often will slow punitive practices, since both regulators and innovators would have a better understanding of mutual expectations. We should not force innovators to conform to old rules written to apply to different ways of doing business - regulators must also innovate. In return, platform companies must be more collaborative. Innovators must recognize that regulators serve an important purpose, and that the safety of their cities should be their goal as well. ${ }^{259}$

255 Airbnb faces criminal liability if it does not comply with San Francisco regulations. See supra text accompanying note 204; see also, Carolyn Said, Airbnb, Under the Gun, Is Ready to Cooperate with SF, S.F. CHRONICLE (Nov. 14, 2016), http://www.sfchronicle.com/business/article/Airbnb-under-the-gun-is-ready-to-cooperatewith-10612040.php [perma.cc/85U8-WTUK].

${ }^{256}$ See supra Part II.

${ }^{257}$ Instead of focusing on perfecting their business model, Airbnb has had to focus largely on regulatory battles. See Benner, supra note 205.

${ }^{258}$ NYU Stern School of Business Professor Arun Sundajararajan states that regulatory battles and regulation are still the biggest sources of uncertainty about Airbnb's future revenue streams. See Katie Benner, Airbnb Settles Lawsuit with Its Hometown, San Francisco, N.Y. TIMES (MAY 1, 2017), https://www.nytimes.com/2017/05/01/technology/airbnb-san-franciscosettle-registration-lawsuit.html.

${ }^{259}$ The authors recognize that there are a number of obstacles that could arise through their suggested process. First it is difficult to identify the stakeholders. Second, within the design- 


\section{CONCLUSION}

\section{The Benefits of a Design-Thinking-Based Regulatory Process}

The impact of regulatory capture and other barriers to entry created by traditional regulatory processes can be seen in both the taxi and the hotel industries. In the taxi industry, the practice of limiting the number of licensed drivers $^{260}$ allowed demand to swell far past supply. This permitted taxi companies to get lazy and not innovate with new technology (no reason to create an expensive online demand system) or upgrade the rider experience (cars were dirty, drivers were rude, minority riders were routinely not picked up). ${ }^{261}$ This happened in cities around the country and created a pain point that the ride-sharing companies exploited to rapidly build a large user base. That large base was then used as leverage when state and local governments attempted to regulate the companies. ${ }^{262}$

thinking framework, regulators will function in entirely different roles and become active agents in their industries. Third, the possibility of regulatory capture in the design-thinking framework may remain; this is especially risky because regulators will spend more time interacting in preliminary phases with innovative new companies. See Armitage, supra note 30. While design thinking may not be perfect, it may very well be a better system than what presently exists. Winston Churchill once conveyed a similar view of democratic government. Cf. Winston Churchill, Speech Before House of Commons 11/11/49, cited by World Association of International Study (WAIS) Forum on Democracy http://wais.stanford.edu/Democracy/democracy_DemocracyAndChurchill\%28090503\%29.ht $\mathrm{ml}$ [https://perma.cc/ZW3J-JGRS] (quoting Winston Churchill's famous admonition that "[i]t has been said that democracy is the worst form of government except for all the others that have been tried.").

${ }^{260}$ See Van Gelder, supra note 62.

${ }^{261}$ See Downes, supra note 41 ("Look inside a typical taxicab today and you'll find little in the way of technological sophistication. Just a meter (introduced in 1897), a two-way radio (circa 1940), and maybe a GPS device (not likely - after all, getting lost earns you more money).").

${ }^{262}$ See Derek Thompson, How Uber's Taxi App Is Changing Cities, ATLANTIC (Nov. 23, 2013), http://www.theatlantic.com/business/archive/2013/11/how-ubers-taxi-app-is-changingcities/281451/ [perma.cc/XN4B-KQUW] (describing a late-night attempt to pass a law to effectively ban Uber prompted a voracious social media response, including 37,000 tweets, which eventually defeated the so-called Uber Amendment); Airbnb has also used this technique, spending $\$ 8$ million to defeat a proposition in San Francisco that would have restricted short-term rentals. See Alejandro Lazo, San Francisco Voters Reject Airbnb Initiative, WALL ST. J. (Nov. 4, 2015), http://www.wsj.com/articles/san-francisco-votersreject-airbnb-initiative-1446622854. 
Similarly, the hotel industry complied with regulations to protect guests and employed union workers on their properties. This resulted in expensive rates that were acceptable in the world of business travelers, but ignored the desires and financial realities of those who wanted to travel for fun and adventure, who desired uniqueness in accommodations and could not or did not want to pay for the same room in the same hotel room everywhere they went. The hotel industry's blindness to this type of user permitted the home-sharing companies to explode on the scene, offering a unique experience at any price. ${ }^{263}$

Thus, the failure of various industries to accommodate users limits growth and innovation. Stagnant regulations then artificially protect companies from outside pressures that would otherwise force them to reinvent their business models as technology and populations change. Nevertheless, the importance of regulations cannot be denied. Without such protections, consumer harm is more likely. This is not just an abstract concept-harm occurs often when regulations don't exist or are not sufficiently stringent. For example, lax regulations were largely blamed for the Grenfel Tower fire in London, where flammable materials were used as exterior siding, resulting in more than 70 deaths in a fire that quickly exploded out of control. ${ }^{264}$ In the ride-sharing space, the lack of adequate insurance was ignored until a little girl was run over by an Uber driver. ${ }^{265} \mathrm{As}$ a result of that accident, the California Department of Insurance worked with private insurance companies to develop a product that would cover a driver engaged in commercial activities. Airbnb had a similar issue when a guest trashed a host's property before leaving and now guarantees hosts $\$ 1,000,000$ in insurance to protect against such damage. These sorts of insurance policies might well have been

${ }^{263}$ One hospitality website estimates that seventy-eight percent of consumers are now looking for personalization in their consumption. Anderson Conte, 3 Things Hoteliers Can Learn From Airbnb's User Experience, CVENT (Sept. 16, 2016), https://blog.cvent.com/hospitality/sales-marketing/airbnb-user-experience/ [perma.cc/CXR4MU54]. Hotels, having realized the profitability of the market Airbnb discovered, are now advertising "local" experiences; see also Liz Moyer, Hotels, Feeling the Pinch of Airbnb, Promote Local Experiences, N.Y. TIMES (May 29, 2017), https://www.nytimes.com/2017/05/29/travel/hotels-feeling-the-pinch-of-airbnb-promotelocal-experiences.html [perma.cc/KNJ5-2LUX].

${ }^{264}$ David D. Kirkpatrick, et al., Why Grenfell Tower Burned: Regulators Put Cost Before Safety, N.Y. TIMES (June 24, 2017), https://www.nytimes.com/2017/06/24/world/europe/gren fell-tower-london-fire.html?_r=0 [perma.cc/RNU3-TBWG].

${ }^{265}$ See Flowchart of Public Rulemaking Process in California, supra note 45. 
developed within a design-thinking collaborative process with all stakeholders contributing their expertise to foresee possible problems.

These examples point out another issue with respect to the current regulatory regime. It is a reactive system in which regulators generally wait for a problem to arise before getting involved. The reactive deliberative process of traditional regulation may have been appropriate when product and service development cycles were slower and user uptake gradual. In such a system, regulators could be informed of problems before users were harmed. With fast-paced, innovative companies, regulators need to be educated and informed about what is taking place in the industries they regulate so that issues can be spotted in advance and dealt with in a timely and thorough manner. In order for that to happen, the regulatory process must be nimble, flexible and user-focused. In the past, that has not been the approach and it has led to much money, time, and effort being wasted by both regulators and entrepreneurs. However, with the future of driverless cars arriving quickly some regulators have adopted new procedures and proactively issued rules or at least principles to guide these cars as they are developed. ${ }^{266}$ Of course, more must be done to ensure that driverless cars and their passengers are safe on our roads, but there is hope for thinking that traditional patterns of regulation may be open to change when guidelines have been issued by the federal government as well as state government years before the products are ready to be launched publicly.

A new regulatory process using design thinking to create new rules for an industry that is about to be disrupted would have many advantages. Any jurisdiction utilizing such an approach would have an advantage recruiting new companies to the area because founders would know that regulators want to find a way to support their businesses and that the municipality or region is

\footnotetext{
${ }^{266}$ In an example of design-like thinking, the National Highway Safety Traffic Administration issued guidelines on autonomous vehicles last fall. See Alex Davies, The Feds Just Got Real About Self-Driving Cars (It's About Time), WIRED (Sept. 19, 2016), https://www.wired.com/2016/09/feds-just-got-real-self-driving-cars-time/ [perma.cc/CN6TYEJB] (quoting President Obama as saying "[g]overnment sometimes gets it wrong when it comes to rapidly changing technologies. That's why this new policy is flexible and designed to evolve with new advances."). In the absence of federal legislation, many states have written their own laws governing autonomous vehicles. However, Congress is currently considering preempting all state laws with respect to autonomous vehicles and replacing them with national standards. See, e.g., Aarian Marshall, Congress Finally Gets Going on that Regulating Robocars Thing, WIRED (June 21, 2017), https://www.wired.com/story/congressautonomous-self-driving-car-regulations/ [perma.cc/2TJB-WTML].
} 
itself innovative and thus likely to be good place to launch new ideas. ${ }^{267}$ Regulators would be happy with the process because they would not have to wait for a consumer harm or public outcry shaming their lack of effective response before being able to investigate the issue. ${ }^{268}$ Moreover, a pilot regulation designed by all stakeholders is likely to include more data and information so that a regulator would have ways to measure the impact of the rules. In this way, regulation will become performance-based and data-driven. Overall, the economy of the area would be more efficient, with less time and money spent on confrontation, with a level playing field for old and new companies in an industry, and with the private and public assets of the community better utilized. For these reasons, design thinking can produce a regulatory process that is a winning situation for everyone involved.

\footnotetext{
267 Technology has driven San Francisco's economic boom. See Jennifer Warburg, Forecasting San Francisco's Economic Future, SPUR (Feb. 27, 2014), http://www.spur.org/news/2014-02-27/forecasting-san-francisco-s-economic-fortunes [perma.cc/N5QB-D84E].

${ }^{268}$ Brian Jackson Green, Why Are Regulators so Out of Touch?, ILL. POL'Y (Mar. 11, 2014), https://www.illinoispolicy.org/why-are-regulators-so-out-of-touch/ [perma.cc/R37H-FGZJ] (describing when state and local officials confront innovation, they rush to prohibit and harass it under the guise of protecting the public); see Felix Salmon, When Disruption Meets Regulation, REUTERS (Jan. 30, 2014), http://blogs.reuters.com/felix-salmon/2014/01/30/whendisruption-meets-regulation/ [perma.cc/GH57-EVWH] ("From the point of view of Silicon Valley libertarians, the idea that they're disrupting a long established flow of public monies is a feature, not a bug.").
} 